\title{
Phonological and conceptual activation in speech comprehension
}

\author{
Dennis Norris ${ }^{\mathrm{a}, *}$, Anne Cutler ${ }^{\mathrm{b}}$, James M. McQueen ${ }^{\mathrm{b}}$, \\ Sally Butterfield ${ }^{\text {a }}$ \\ ${ }^{a}$ MRC Cognition and Brain Sciences Unit, Cambridge, UK \\ ${ }^{\mathrm{b}}$ Max Planck Institute for Psycholinguistics, Nijmegen, The Netherlands
}

Accepted 8 March 2006

Available online 23 June 2006

David A. Swinney, who originated the cross-modal priming task and thus significantly furthered the study of spoken-language processing, died in April 2006. This paper is dedicated to his memory.

\begin{abstract}
We propose that speech comprehension involves the activation of token representations of the phonological forms of current lexical hypotheses, separately from the ongoing construction of a conceptual interpretation of the current utterance. In a series of cross-modal priming experiments, facilitation of lexical decision responses to visual target words (e.g., time) was found for targets that were semantic associates of auditory prime words (e.g., date) when the primes were isolated words, but not when the same primes appeared in sentence contexts. Identity priming (e.g., faster lexical decisions to visual date after spoken date than after an unrelated prime) appeared, however, both with isolated primes and with primes in prosodically neutral sentences. Associative priming in sentence contexts only emerged when sentence prosody involved contrastive accents, or when sentences were terminated immediately after the prime. Associative priming is therefore not an automatic consequence of speech processing. In no experiment was there associative priming from embedded words (e.g., sedate-time), but there was inhibitory identity priming (e.g., sedate-date) from embedded primes in sentence contexts. Speech comprehension therefore appears to involve separate distinct activation both of token phonological word representations and of conceptual word representations. Furthermore, both of these types of representation are distinct from the long-term memory representations of word form and meaning.
\end{abstract}

(c) 2006 Elsevier Inc. All rights reserved.

\footnotetext{
* Corresponding author. Fax: +44 1223359062.

E-mail address: dennis.norris@mrc-cbu.cam.ac.uk (D. Norris).
} 
Keywords: Psycholinguistics; Priming; Speech

\section{Introduction}

Understanding spoken language requires the conversion of sound to meaning. Words are the units of meaning expressed in sound. The process of word recognition is thus the heart of language understanding. The central concern of this paper is the involvement in this process of separate lexical representations based on sound and based on meaning.

A separation between phonological representations (representations based on sound) and conceptual representations (representations based on meaning) is assumed in many psycholinguistic approaches to lexical processing; thus current models of language production (e.g., Dell, Schwartz, Martin, Saffran, \& Gagnon, 1997; Levelt, Roelofs, \& Meyer, 1999) all distinguish between representations involving semantic and syntactic information and representations involving phonological form. The literature on word recognition, in contrast, has given rather little attention to distinguishing sub-components of lexical representations involved in the recognition process, since such distinctions are not required to explain the primary data on which the theories are built (time to accept a word as an existing form, or accuracy in doing so).

The present paper is concerned with this hitherto neglected issue. In a series of priming experiments we vary aspects of the task in such a way that we can observe the separate contribution of different components of lexical representations in spoken-word recognition. We will show that phonological and conceptual representations participate separately in the recognition process; we can further distinguish type from token representations; and we will show that these distinctions are necessary to give a full and correct account of how words are understood.

Most current recognition models, either in the visual or the spoken domain (e.g., McClelland \& Elman, 1986; McClelland \& Rumelhart, 1981; Morton, 1969; Norris, 1994; see McQueen, 2005, for a recent review), are based upon a metaphor of lexical activation: Perceptual input, visual or spoken, activates lexical representations, and the level of activation of any word is determined primarily by the degree of match between the perceptual input and the word's stored representation. In such theories, each lexical representation that is activated is a unitary node (e.g., a local representation in a connectionist model) or a simple feature counter (e.g., a logogen). Recognition occurs when the activation of a lexical representation exceeds some threshold criterion. Although the models thus incorporate lexical representations without further specification, in fact it is easy to distinguish separate levels of representation in the models' actual operation. For example, in both TRACE (McClelland \& Elman, 1986) and Shortlist (Norris, 1994) there is a distinction between the representation of a word in the mental lexicon itself, and the lexical candidates involved in the recognition of any particular utterance. Whereas there is only one lexical entry for each word in the listener's mental lexicon, there will be multiple representations of the lexical candidates corresponding to each word. It is necessary that more than one token of each lexical candidate be possible, otherwise utterances containing more than one token of a given word could not be processed. Consider, for example, the three tokens of /si:t/ involved in recognizing the sentence "Everyone's receipt for tomorrow's concert seat will be on their seat at dinner"; one token is spuriously present as part of a longer word, while 
the other two tokens are phonological representations in their own right, but associated with conceptual representations which are, arguably, quite distinct.

The concurrent activation of multiple lexical candidates allowed for in models of this type is resolved by competition; activated candidates compete with one another, the outcome being an optimal interpretation of the likely sequence of words in the input. The competition process is performed by an interactive activation network, with overlapping word candidates connected by inhibitory links. In the above example sentence, we assume therefore that separate phonological representations of seat will compete with (in one case) a representation of receipt and (in another case) with alternative fully or partially supported candidates such as see, cedar or perceive. A single lexical entry for seat could thus nevertheless support multiple instances of the phonological form /si:t/ representing multiple tokens in the competition.

Competition with inhibition has proven remarkably effective in accounting for the recognition of words in running speech. Because of the lack of clear and reliable cues to the location of word boundaries in continuous speech, some mechanism is required that can determine which sequence of words best matches the input. The competition process achieves this in models of the TRACE/Shortlist type. Norris (1994) illustrated how it does so by considering the spoken input ship inquiry. After the first two syllables of this input, shipping is likely to be a better match to the input than ship. However, by the end of the utterance, inquiry will have inhibited shipping, and this will prevent ship being inhibited by shipping. The competition between overlapping words enables these models to arrive at the correct lexical parse of the input (i.e., here ship inquiry). Importantly, even if shipping remains a better match to part of the input than ship, inhibition of the latter part of shipping by inquiry ensures that ship becomes part of the preferred interpretation of the utterance.

Competition also allows for the rejection of words which are only spuriously present in the input; note that normal speech contains a very large number of such words (McQueen, Cutler, Briscoe, \& Norris, 1995). Spuriously present words can be embedded within other words (e.g., seat in receipt) or they can occur across word boundaries (e.g., below in terrible omen). In competition models, these embedded words all enter into the competition process that determines the correct interpretation of the utterance. The competing representations of spuriously present words will ultimately lose the competition, and little evidence of their presence will in the end be discernible if the process has run its course in the intended way. However, their participation in the competition is an essential component of this view of spoken-word recognition.

As we shall see in the next section, the activation metaphor incorporated in the current models has been extremely fruitful in stimulating spoken-word recognition research. There is abundant evidence in support of multiple concurrent activation, including evidence concerning spuriously present words, and there is evidence supporting a role for inhibition as instantiated in competition models.

\subsection{Testing activation}

Since its introduction by Swinney (1979; see also, Swinney, Onifer, Prather and Hirshkowitz, 1979) the cross-modal priming task has proven the task of choice for examining the activation of lexical representations. In cross-modal priming experiments, participants typically hear a prime (a word or a sentence) and then see a target word. An influence of the relationship between prime and target on responses to the target (e.g., speed or accuracy of lexical decisions) is taken as an indication of lexical activation, first for the prime, 
then spreading from the prime to the target. For example, in Swinney's (1979) study, listeners heard polysemous prime words such as bug in sentences and made lexical decisions to visually presented target words that were associates of each of the meanings of the primes (e.g., spy and ant for bug). Responses to both targets were facilitated (in comparison to a control target), which Swinney interpreted as indicating that both meanings of the polysemous prime had been activated.

In the first years of research with the task, all cross-modal priming studies involved associative relationships between prime and target. Clearly, activation of a semantic associate implies that the conceptual representation corresponding to the input word has been activated. Since the late 1980s, however, cross-modal priming has existed in two variants: besides cross-modal associative priming we have cross-modal identity priming, in which the target is a visually presented token of the prime word. Identity priming does not necessarily imply that conceptual representations have been activated, though of course facilitation in an identity priming study does imply that a phonological representation has been activated by the input.

The two variants of cross-modal priming make it tempting to imagine that each variant could be used to examine activation of a different kind of representation. Unfortunately, the pattern of possible priming relationships (or absence thereof) is rather more complicated than such a simple picture would require; we see three problems which stand in the way. First, it may be the case that separate phonological and conceptual representations are involved in spoken-word recognition, but they are tightly coupled such that activation of one necessarily implies activation of the other. In that case, there would be little distinction between results with the two types of cross-modal priming. Second, the relationship between activation and priming is not symmetric; while priming may well imply activation, the reverse is not the case. There is no guarantee that a representation that is accessed or activated during the course of word recognition will lead to detectable priming. This means that priming does not provide a magic window onto the inner workings of word recognition, and that different types of priming cannot be translated as implying activation of different types of representations. Third, it is often unclear whether activation of a prime will cause recognition of a related target to be facilitated, or, due to the pattern of activation of competitor words, to be inhibited. Again, this means that predicting patterns of results with priming tasks is far from simple.

The priming literature does not provide an agreed basis for such prediction. Semantic priming, for example, has variously been proposed to be due to spreading activation (Collins \& Loftus, 1975; McNamara, 1992), compound cueing (Ratcliff \& McKoon, 1988), plausibility checking (Norris, 1986), feature overlap (Huber, Shiffrin, Lyle, \& Ruys, 2001), or a hybrid of multiple mechanisms (Neely \& Keefe, 1989; Neely, 1991). Most of these theories have been developed in the context of single word priming studies; they assume that a single prime word is activated and that priming follows from the activation of that single word. Similarly, accounts of sentence context effects (Kintsch, 1988) assume that the listener or reader establishes a single representation of the context, and that it is this single representation that leads to priming. However, in spoken-word recognition, evidence forces us to accept that multiple candidate words are simultaneously activated (see McQueen, 2005, for review). Theories of priming do not make it clear, a priori, whether all of these candidates should produce priming, or whether only the most highly activated candidates should do so. Thus, the literature does not allow us to resolve the first problematic issue, whether separate representations may be separately activated. 
According to some theories, semantic priming is produced by the lexical access process itself. For example, in the location-shifting theory of Meyer and Schvaneveldt (1971), or Forster's (1976) search model, semantic or associative priming is a consequence of the structure of the lexicon. This structure reflects semantic relationships between words, and semantic priming thus follows from lexical access rather than from the activation of specific semantic representations. A similar argument applies to spreading activation models. Accessing a lexical entry might produce associative priming by the spread of activation to other entries, even in the absence of any semantic representations being constructed during the recognition process. The implicit theory underlying the use of priming as a tool indeed appears to be that lexical activation will automatically produce associative priming by means of a mechanism such as spreading activation.

In the case of both spoken and visual word recognition, however, lexical access alone may not be sufficient to produce semantic priming. As we shall see below, Williams (1988) and Tabossi (1988a) both failed to find cross-modal associative priming from words in spoken sentences when the targets were not related to the overall meaning of the sentence. Likewise, in the reading literature, Friedrich, Henik, and Tzelgov (1991) have shown that when subjects are required to perform a letter search task on a prime word, this eliminates semantic priming but not identity priming. Results such as these cast doubt on simple accounts of priming based on spreading activation. That is, lexical access need not lead automatically to semantic activation. The second problem, concerning the logical relation of priming to activation, thus seems to be one which indeed bedevils priming research.

The third problem, of potential inhibitory as well as facilitatory priming effects, also needs to be considered. Inhibitory processes can mask lexical activation: Even when there is clear evidence that a representation of a word has been activated, there may be no observable priming if inhibitory processes immediately suppress the initial activation. Thus as Marí-Beffa, Houghton, Estévez, and Fuentes (2000) have pointed out, absence of priming cannot be taken as evidence of absence of activation. When subjects are required actively to ignore either a word or an individual object, related targets can actually be inhibited (e.g., Dalrymple-Alford \& Bundayr, 1966; see Marí-Beffa et al., 2000, for review). Tipper (1985) described this process as "negative priming." Marí-Beffa et al. manipulated the task subjects had to perform on the prime. When the task was detection of letters in the prime word, priming of visual lexical decisions to target words was small and facilitatory. But when the prime task was detection of letters in a separate letter string, and the prime word had to be ignored, priming was inhibitory. This kind of negative priming clearly indicates that the word was semantically activated even when it had to be ignored. Thus it is important to take account of both possible positive and negative effects in priming studies.

With these provisos in mind, it is perhaps not so surprising that the cross-modal priming literature presents, as the following review shows, a complex pattern.

\subsection{Cross-modal associative priming}

The first decade and a half of associate priming research is summarised by Tabossi (1996). Primes in isolation produced robust facilitation (e.g., Andruski, Blumstein, \& Burton, 1994; Bölte \& Coenen, 2002; Marslen-Wilson \& Zwitserlood, 1989; Swinney, Onifer, Prather, \& Hirshkowitz, 1979; Williams, 1988). Primes in sentences on the other hand have not always been so reliable. Swinney et al. (1979) and Lucas (1987) and Shillcock $(1982,1990)$ were among those who reported significant associative priming 
effects in sentences. The first failures of cross-modal associative priming in sentence contexts were reported by Williams (1988) and Tabossi (1988a). Williams found that primes which produced reliable associative facilitation in isolation (chair-table) and in random word lists (table after chair in "when brass heard could in that only land as more film to interested to is chair because which came could all ice in") did not produce any facilitation in perfectly sensible sentences which were not relevant to the particular associative relationship involved in the prime-target pair (table after chair in "The man found that he could only reach the best apples by standing on a chair because they were all so high up"). There was, however, significant facilitation in "The man entered the dining room and sat down on a chair in eager anticipation of a hearty meal." Williams argued that associative relationships are not automatically called up by lexical access of the prime words, but are only available in what Foss and Ross (1983) termed the "effective context" for priming, that is, the propositional representation of the sentence as a whole. If the associative relation in question (e.g., chair as something on which one sits at a table to eat dinner) is relevant to the propositional representation (e.g., a man is about to eat dinner), there will be priming of that association. If it is not relevant to the proposition (e.g., a man has to stand on a chair to reach something), there will be no priming. However, when the words appear in a list, the only effective context is provided by the words themselves, and this will lead to priming.

Similarly, Tabossi (1988a) found no priming when the sentences were biased toward an aspect of the meaning of the (sentence-final) prime that was not related to the target (e.g., responses to fat were not primed after the sentence "To soften it, the woman heated a piece of butter"), but significant facilitation when the sentences were biased toward semantics shared by the prime and the target (e.g., responses to fat were faster relative to control conditions after "To follow her diet, the woman eliminated the use of butter"). Tabossi argued that the activation of lexical semantics is context-sensitive; that is, semantic activation depends on the current interpretation of the utterance. This interpretation is clearly similar to the effective context proposal. Williams' and Tabossi's results are also consistent with data reported by Hess, Foss, and Carroll (1995) from nine experiments involving a slightly different task. Participants heard short prose passages and had to name the final word, which was presented visually. Hess et al., too, found no contextual facilitation from local lexical information; facilitation was only found if the target word was related to the global discourse context. These results made it clear that one important factor in determining whether priming will be observed is the extent to which the prime words are related to the overall meaning of the sentence or discourse.

Another factor affecting the likelihood of observing associative priming is where the prime appears relative to the end of the sentence. Several experiments have reported priming when the sentences are terminated immediately after the offset of the prime-either whole word primes (Moss \& Marslen-Wilson, 1993) or word-fragment primes (i.e., only the initial portions of longer words; Tabossi, Collina, Mazzetti, \& Zoppello, 2000; Zwitserlood, 1989; Zwitserlood \& Schriefers, 1995). Gow and Gordon (1995) terminated their speech materials (with embedded-word primes) when participants responded to the targets, that is, at variable times soon after prime offset. Truncation of a sentence of which a representation is being constructed may encourage listeners to attend to the primes, disrupting the construction of sentence-level representations. This would lead to stronger activation of the meaning representations of the primes, and hence activation of associated words, and a priming effect. 
Even when listeners are presented with complete sentences, the presence of primes at the end of sentences may draw listeners' attention to the prime words, especially if most of the primes in an experiment appear at the end of sentences. Many of the studies that have reported associative priming in sentences have indeed used sentence-final primes (Janse, 2003; McKoon, Allbritton, \& Ratcliff, 1996; Seidenberg, Tanenhaus, Leiman, \& Bienkowski, 1982; Simpson, 1981; Tabossi et al., 2000). Note, though, that Tabossi (1988a), as described above, found no priming from sentence-final words when the target was unrelated to the overall meaning of the sentence, and in one of Williams's (1988) experiments, sentence-final primes similarly failed to produce associative priming.

In some studies in which priming has been observed, the primes appear mainly at the end of clauses or at points indicated with a comma in the transcription of published materials (Colombo \& Williams, 1990; Onifer \& Swinney, 1981; Tabossi, 1988b; Tabossi, Colombo, \& Job, 1987; Tabossi \& Zardon, 1993). In Cutler (1986) and Lucas (1987), the primes appeared neither at the end of their context sentences nor systematically before major clause boundaries. They appeared, however, relatively late in long sentence contexts which were heavily biased towards one or other meaning of the (ambiguous) primes. Similarly, in yet other experiments, discourse context was provided in the form of a context sentence which preceded the sentence containing the prime (Blutner \& Sommer, 1988; Swinney, 1979, Experiment 1). The presence of a discourse context may encourage listeners to process sentences in greater depth and incorporate more of the meaning of the prime into the interpretation of the sentence. (Note, however, that discourse sentences are not necessary for associative priming to emerge. In most studies, no such contexts are provided. Furthermore, Swinney (1979, Experiment 2) also found priming without preceding context sentences.)

Thus, the variability in associative priming may depend on a number of factors, all of which act to modulate the kind of interpretations which listeners build of the test utterances. Priming is more likely to be observed if primes are placed in a prominent location (e.g., at the ends of sentences or clauses, or at the end of artificially truncated auditory material), or if the prime-target associative relationship is relevant to the meaning of the sentence. Nonetheless, none of these factors guarantees the appearance of significant priming effects, and there are also studies which have detected associative priming from nonembedded words in sentence contexts for which none of the above criteria appears to apply (Shillcock, 1990; Swinney, 1979; Tabossi, Burani, \& Scott, 1995).

\subsection{Cross-modal identity priming}

There is a much smaller body of work so far using the identity-priming version of the task, but it is clear that when the prime and the target are the same word the pattern of results is much more straightforward than when prime and target have an associative relationship. Both when spoken primes are presented in isolation and when they appear in sentence contexts, there is robust facilitation when visual targets are identical to those primes. Given the reliability of this facilitation, cross-modal identity priming has been used to examine whether, in a number of situations in which the phonological form of the prime differs from the canonical form of that word, there is still a priming effect. These situations include the case of phonological alterations due to continuous speech processes such as place assimilation and liaison, and the case of phonetic alterations reflecting variability in the fine-grained realization of spoken words. We will not review these sets of results in 
detail. For current purposes it is sufficient to note that the facilitatory priming effect in the control conditions of these studies (i.e., when the prime has its canonical pronunciation) has been replicated across studies, both for primes in isolation (van Alphen \& McQueen, 2006; Bölte \& Coenen, 2002; Coenen, Zwitserlood, \& Bölte, 2001; Marslen-Wilson, Nix, \& Gaskell, 1995) and for primes in sentence contexts (Coenen et al., 2001; Gaskell \& Marslen-Wilson, 1996, 2001; Gaskell, Spinelli, \& Meunier, 2002; Gow, 2002; Spinelli, McQueen, \& Cutler, 2003). Vroomen and de Gelder (1995) observed facilitatory identity priming from prime words embedded in nonsense contexts.

As with cross-modal associative priming, identity priming has also been examined where the prime consists only of a word fragment. This variant of the paradigm has also been used to examine a number of issues in spoken-word recognition including place assimilation and the uptake of lexical stress information. Control conditions across a number of studies show once again that there is robust facilitation when the prime fragment is a perfect match to the target, both for fragments in isolation (Gaskell \& Marslen-Wilson, 2002; Marslen-Wilson et al., 1995; Cutler \& van Donselaar, 2001) and in sentence contexts (Cooper, Cutler, \& Wales, 2002; Davis, Marslen-Wilson, \& Gaskell, 2002; van Donselaar, Koster, \& Cutler, 2005; Soto-Faraco, Sebastián-Gallés, \& Cutler, 2001).

\subsection{Embedded words}

Of particular interest for the present study is the fact that cross-modal priming has been the task of choice for investigation of the activation in spoken-word recognition of words embedded in other words, such as seat in receipt. Studies of embedded words have mainly used associative priming. Shillcock (1990) found that words such as trombone, presented in sentence contexts, produced priming of responses to the visual word rib, an associate of the embedded word bone. Gow and Gordon (1995) contrasted priming from sentences containing words such as tulips or two lips. They found that two lips primed words related to tulips and to lips, but that there was no priming from tulips to words related to lips. Vroomen and de Gelder (1997) studied the activation of embedded words with isolated Dutch words (rather than sentences) as associative primes; they observed priming from word-final embeddings where the embedded word corresponded to a complete syllable in the embedding word (e.g., boos, 'angry,' in framboos, 'raspberry'), but not when the onset of the embedded word did not coincide with the onset of a syllable (e.g., wijn, 'wine,' in zwijn, 'swine'). Isel and Bacri (1999), using French isolated word primes, found priming for words that formed the final syllable of a longer word, but no priming from onset-embedded words. Luce and Cluff (1998) presented prime words such as hemlock, and found that the offset embeddings (e.g., lock) produced associative priming to words associated not with the carrier words but with the embeddings (e.g., key).

Tabossi et al. (1995) observed evidence of activation of Italian words such as visite 'visit' in phrases such as visi tediati 'bored faces' within sentences. Here visite begins in the same way as visi, but also continues into the beginning of tediati-that is, the embedding is across words. Responses to associates of such embeddings were facilitated.

Identity priming was used by Marslen-Wilson, Tyler, Waksler, and Older (1994) and by Shatzman (2006) to examine activation of embedded words. Marslen-Wilson et al., used spoken primes in isolation, and in line with the results of Isel and Bacri (1999), they found no evidence of activation of word-initial embedded words (e.g., bulletin-bullet). Interestingly, they found an inhibitory priming effect (of $12 \mathrm{~ms}$, on average; non-significant) for 
word-final embeddings (e.g., trombone-bone). A similar inhibitory effect was observed by Shatzman (2006) for Dutch offset embeddings such as bel 'bell' in libel 'dragonfly,' and in this case the effect reached significance.

These results present a picture of embedded-word activation which is not fully consistent. However, we suggest that activation may depend on a combination of effects. First, there are segmentation cues, which are obviously relevant for word boundary detection and hence for deciding what particular string constitutes a separate word. Gow and Gordon (1995) suggested on the basis of their pattern of results that there was cross-modal associative priming in their materials only when the onset of the word was acoustically marked. Note that segmentation cues were also present in the Shillcock (1990) materials: The carrier words all had weak-strong stress patterns (i.e., the first syllables were either weak, as in descend, or had secondary stress, as in trombone). In English, the onsets of strong syllables provide an important cue for lexical segmentation (Cutler \& Norris, 1988; Norris, McQueen, Cutler, \& Butterfield, 1997), so bone in trombone began at a segmentation point. Syllabic alignment was present in the cases where Isel and Bacri (1999) observed facilitation for offset-embedded words, which is likewise consistent with claims that the syllable cues lexical segmentation in French (see Cutler, McQueen, Norris, \& Somejuan, 2001, for review). Syllabic alignment was also the prerequisite for the effect observed in Dutch by Vroomen and de Gelder (1997). Thus activation of offset-embedded words may depend primarily on the presence of segmentation cues.

Second, there are also effects of the lexical competition process. Although cross-word embeddings such as visite in visi tediati appear to be activated (Tabossi et al., 1995), and although this suggests that word-internal onset embeddings (car in cargo) are also likely to be briefly activated, there is no sign of activation of such onset-embedded words by the end of the longer competitor (Isel \& Bacri, 1999; Marslen-Wilson et al., 1994). This is presumably due to effects of competition. Note that although Tabossi et al. used sentence materials rather than isolated words, and they studied a different kind of embedding from the word-internal embeddings studied by Isel and Bacri, there is another critical difference between these two studies, to wit, the presentation point of the target words. Isel and Bacri presented their targets at the offset of the longer carrier word (e.g., cargo), by which time the embedded word (car) could have already been activated and then suppressed through competition with the carrier. Tabossi et al., however, presented their target words at the offset of the cross-word-boundary embeddings (e.g., at the offset of visite). At this point, there is more bottom-up support for the embedding than for the intended word (visi). Tabossi et al. may thus have been more likely to detect activation of the unintended word before it was inhibited by its competitors. We suggest, therefore, that activation of onsetembedded words depends primarily on competition.

\subsection{Summary}

The picture revealed by our review obviously motivates further research. In particular, the possibility that cross-modal identity priming and cross-modal associative priming are tapping into different types of representation has not previously been subject to direct investigation. The present experiments therefore sought to establish what kind of representations of lexical phonological form and of lexical meaning are involved in speech comprehension, and to examine the relationship between word-form and word-meaning representations. The simplest model that we consider is one in which the phonological and 
conceptual representations of each word exist as separate but tightly linked parts of the same lexical entry in long-term memory. As we have argued, such a model predicts that identity- and associative-priming effects should go hand in hand. We will compare this model with one in which a distinction is made between stored lexical representations (both phonological and conceptual knowledge) and the token-based representations of words which are used during the on-line processing of any particular utterance. This latter model predicts that identity- and associative-priming effects can (but need not) dissociate, perhaps, for example, as a function of whether words are embedded or not.

Our first experiments attempted to replicate Shillcock (1990), first in isolated words (Experiment 1A), and then in sentences (Experiment 1B). We thus used cross-modal associative priming to examine the activation of conceptual representations of embedded words (e.g., date in sedate) and of the same words when the speaker actually intended them (e.g., date). We predicted on the basis of the previous research on embedded words that we would observe activation of the semantics of a word such as date whether it was what the speaker intended or it was an embedded word. We also manipulated the ISI between the offset of the critical auditory word and the onset of the visual target word, to determine whether the pattern of priming changed over time.

The Shillcock (1990) results are particularly important with respect to the question of whether there are distinct type- and token-based lexical representations. For the offset embedding boneltrombone, for instance, both TRACE and Shortlist predict that the lexical node corresponding to bone should be strongly inhibited by concurrent activation of trombone. Simulations from Shortlist are presented in Fig. 1. Activation of the embedded word is almost completely suppressed by the activation of the longer word. TRACE has a similar lexical competition process to that in Shortlist, and thus makes similar predictions about the activation of embedded words (cf. McClelland \& Elman, 1986, Figure 27). Thus Shillcock's (1990) results would seem to contradict one of the central predictions of Shortlist and TRACE. In contrast, both Shortlist and TRACE predict the pattern found with carrier words such as Luce and Cluff's (1998) hemlock. Here, both embedded words hem and

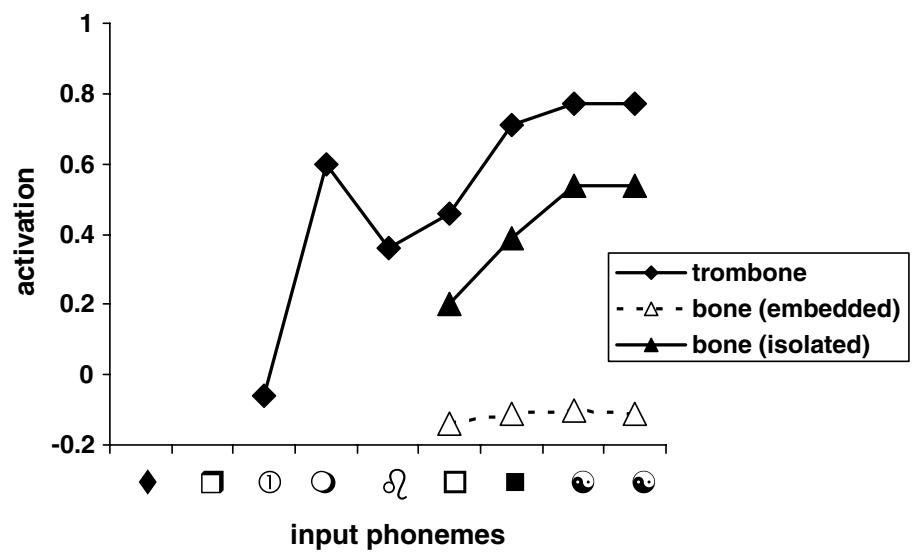

Fig. 1. Shortlist simulations. The activation of the lexical candidates trombone and bone is plotted over time, as the successive phonemes of the input trombone were presented to the model. Note that "[" represents a segment of silence. For comparison, the activation of the candidate bone, given the input bone, is also plotted, aligned with the embedded word sequence in the longer word. 
lock will compete with the carrier, and the shorter embedded words tend to be of higher frequency than the longer carriers. In this case activation of the final embedded word is unlikely to be completely suppressed by the carrier word, so that activation of the offset embedding is stronger than when there is no onset embedding as well.

The inhibition for offset-embedded words observed with identity priming by MarslenWilson et al. (1994) and Shatzman (2006) further seems to conflict with the facilitatory effects found with associative priming (e.g., Shillcock, 1990). However, this difference may arise because the two types of task are tapping into different types of lexical representation. Indeed, the conclusions that can be drawn from all these priming studies depend critically on establishing which representations drive associative and identity priming. If, for example, access to stored phonological knowledge about a word is itself sufficient to produce associative priming, then the results may be fully consistent with a model like Shortlist, which, as described earlier, has a separate stage of lexical access. Mere entry of an item into the competition process may be sufficient to lead in due course to associative priming, while the inhibition measured in identity priming may reflect the competition between token-based representations shown in Fig. 1. To examine this possibility, we directly compared cross-modal associative priming with cross-modal identity priming. Experiment 2 used identity priming with the materials from Experiment 1.

We also tested whether associative priming could be modulated by the overall context in which the prime appears. As mentioned earlier, there is evidence that associative priming can be found for words in isolation, but not when the same words appear in sentences. This suggests that priming may be driven by the listeners' overall interpretations of sentences, rather than by the activation of individual word-meaning representations. Such a dissociation would be inconsistent with the notion that associative priming is an automatic consequence of lexical access. We therefore contrasted isolated primes (Experiment 1A), with primes in sentences (Experiment 1B).

In Experiments 3 and 4 we attempted to manipulate the way associative primes were processed in sentence contexts by altering, in turn, aspects of the experimental design (Experiment 3), the semantic complexity of the prime-bearing sentences (Experiment 4B), or the prosodic contours of the sentences (Experiment 4C).

\section{Experiment 1: Associative priming}

\subsection{Experiment 1A: Prime words in isolation}

\subsubsection{Method}

2.1.1.1. Materials. The stimuli were based on those used by Shillcock (1990). The critical items were the set of 32 bisyllabic words shown in Appendix A. These words were selected such that the final syllable of each of them was homophonous with a real word (e.g., date in sedate). The embedded words did not need to be orthographically identical to the final syllable of the carrier bisyllabic word (e.g., stream in extreme). They could also be homophones (e.g., either night or knight in ignite). A critical requirement was that the carrier word and the embedded word should be semantically unrelated. Carrier words in which the first syllable's pronunciation corresponded to that of an independent word were excluded. Thirty of the 32 carriers had a weak-strong prosodic pattern (i.e., either the first syllable had the reduced vowel schwa, as in the majority of cases, e.g., sedate, or the first syllable had a full vowel, but primary stress was on the second syllable, e.g., trombone). 
Most of the carriers were monomorphemic, but a few could be considered to be prefixed with bound stems (e.g., report, protest, and decrease). In these cases, however, the stems were semantically unrelated to the embedded word. According to Marslen-Wilson et al. (1994), there should therefore be no morphological priming from the carrier word to the embedded word. One of the carriers was a tensed verb (begun).

Semantic associates of the embedded words were generated by presenting listeners with a recording of a set of 56 possible experimental items. Listeners (who did not take part in the main experiment) were instructed to write down, immediately after hearing the word, the first word it brought to mind. Only those words for which $25 \%$ or more of the listeners provided the same associate as response were included in the experiment proper. The mean association strength of the selected items was $44.7 \%$.

The experimental materials therefore consisted of 32 pairs of carrier bisyllabic words and their embedded monosyllabic words, which served as auditory primes, and a further 32 words, each of which was associated to an embedded word, which served as visual targets. There were, in addition, 48 filler prime-target pairs. The fillers consisted of 16 monosyllabic primes and 24 bisyllabic primes which were followed by non-word targets, and eight bisyllabic primes which were followed by word targets that were related to the primes (e.g., concern-worry). These eight prime-target pairs were included to ensure that participants could not assume that targets, if related, would always be related either to the monosyllabic words embedded in the carriers or to the isolated versions of those monosyllabic words. Sixteen of the bisyllabic primes with non-word targets had embedded words in their second syllable (e.g., defense-drow, with fence as the embedded word). The presence of these items meant that primes with embeddings were not predictive of word targets. All of the non-word targets were orthotactically legal English pseudowords. Finally, there were ten practice prime-target pairs; at least one example of each of the prime-target pairings (i.e., with respect to the lexical status of the targets, and the relatedness of the word targets to the prime or the embedded word in the prime) was included in the practice set.

2.1.1.2. Design. There were four priming conditions, created by crossing the length of the auditory prime (non-embedded vs. embedded) with the associative relationship between the prime and the visual target (related vs. unrelated). Each of the target words served in all four conditions (e.g., non-embedded, related: date-time; embedded, related: sedate-time; nonembedded, unrelated: come-time; and embedded, unrelated: succumb-time). To produce these conditions in a fully within-item design, the 32 target words were split into 16 semantically unassociated pairs (e.g., time was paired with go) matched in frequency, using frequency counts for written British English (Hofland \& Johansson, 1982). The combinations of each of the primes with each of the targets in these 16 pairs generated the four conditions (e.g., the prime-target pairs for go were thus: non-embedded, related: come-go; embedded, related: succumb-go; non-embedded, unrelated: date-go; and embedded, unrelated: sedate-go).

Four lists of materials were constructed by counterbalancing the prime-target pairings for each of the experimental target words across the lists, such that each list contained all 32 experimental targets, eight in each of the four priming conditions. All 48 filler targets (eight words and 40 non-words) and their primes appeared in each list. The visual targets were thus balanced on the lexical decision task for "yes" and "no" responses. Within the word targets in any one list, 24 were related (eight of the date-time type, eight of the sedatetime type, and eight of the concern-worry type) and 16 were unrelated. In addition, there were two pseudo-random presentation orders for each list, constructed so that there was 
always at least one filler item intervening between any two experimental items. Note that in all the analyses presented here, data were collapsed over stimulus randomizations or presentation orders. Each participant was presented with one version of one of the lists.

ISI was a between-participants factor. For half of the participants, the visual targets were presented without delay at the offset of the auditory prime ( $0 \mathrm{~ms}$ ISI). For the other participants, there was a $500 \mathrm{~ms}$ delay from prime offset to target onset (500 ms ISI).

2.1.1.3. Procedure. All of the auditory (prime) materials were spoken by a phonetically trained speaker (a male native speaker of British English) who was unaware of the purpose of the experiment. The two words with primary stress on the first syllable (frantic and hiccup) were produced with unreduced second syllables, to ensure proper match of that second syllable to the embedded words (tick and cup). Recordings were made on one channel of a Digital Audio Tape, using a high quality microphone in a sound-proofed room. The stimuli were then transferred to a computer where a speech editor was used to label each word, and to place a timing signal on the unused channel coincident with the offset of each word. The timing signal was inaudible to participants. The speech materials were then written to an audio CD.

Participants were tested individually in a quiet room. They were told that they would hear spoken words, followed by visual stimuli on a computer screen. They were told that some of the visual stimuli would be real words of English, and some would not. They were asked to decide whether these items were words or not, and to respond as quickly and as accurately as possible by pressing either the "yes" or the "no" button on a response pad. Participants were also required to repeat the auditory word immediately after making the lexical decision response. The auditory words were presented over high quality headphones (Sony MDR CD550) driven by a portable CD player. Visual targets were presented on a CRT computer monitor in lower case characters where the height of the tallest character subtended a visual angle of approximately $0.7^{\circ}$. Stimulus presentation and timing were controlled by a laptop computer. Before the main part of the experiment participants received the block of 10 practice trials twice.

2.1.1.4. Participants. The listeners in all of the experiments reported here were native speakers of British English, had no known hearing problems, and had normal or corrected vision. Participants in all experiments were paid a small honorarium. In the $0 \mathrm{~ms}$ ISI condition of this experiment participants were 36 members of the MRC Cognition and Brain Sciences Unit volunteer panel. The data from four participants were discarded because they failed to follow instructions. Participants in the $500 \mathrm{~ms}$ ISI condition were 32 students at St. John's College, Cambridge.

\subsubsection{Results}

The 64 participants whose data were included in the analysis performed the secondary (repetition) task with high accuracy (no participant made more than two repetition errors on the 32 experimental trials, and 41 participants made no such errors). Mean lexical decision reaction times and error rates are shown in Tables 1 and 2, respectively. In this and all subsequent experiments, responses slower than $1800 \mathrm{~ms}$ were considered as errors. In the latency analysis, there was a significant main effect of relatedness: responses to related targets were, on average, $24 \mathrm{~ms}$ faster than responses to unrelated targets $(F 1(1,56)=19.49$, $p<.0001 ; F 2(1,31)=5.65, p<.05)$. There was also a significant main effect of embedding: 
Table 1

Associative priming results, Experiments 1,3, and 4: Reaction times

\begin{tabular}{|c|c|c|c|c|c|c|}
\hline \multirow[t]{2}{*}{ Experiment } & \multirow[t]{2}{*}{$\begin{array}{l}\text { Auditory } \\
\text { materials }\end{array}$} & \multirow[t]{2}{*}{$\begin{array}{l}\text { Inter stimulus } \\
\text { interval }\end{array}$} & \multicolumn{2}{|c|}{$\begin{array}{l}\text { Non-embedded Prime } \\
\text { Prime-target relationship }\end{array}$} & \multicolumn{2}{|c|}{$\begin{array}{l}\text { Embedded prime } \\
\text { Prime-target Relationship }\end{array}$} \\
\hline & & & $\begin{array}{l}\text { Related } \\
\text { date-time }\end{array}$ & $\begin{array}{l}\text { Unrelated } \\
\text { come-time }\end{array}$ & $\begin{array}{l}\text { Related } \\
\text { sedate-time }\end{array}$ & $\begin{array}{l}\text { Unrelated } \\
\text { succumb-time }\end{array}$ \\
\hline \multirow[t]{3}{*}{$1 \mathrm{~A}$} & Isolated words & 0 & 573 & 619 & 633 & 636 \\
\hline & & 500 & 552 & 584 & 576 & 588 \\
\hline & & Combined & 563 & 602 & 604 & 612 \\
\hline \multirow[t]{3}{*}{ 1B } & Sentences & 0 & 543 & 548 & 547 & 551 \\
\hline & & 500 & 552 & 563 & 552 & 561 \\
\hline & & Combined & 547 & 556 & 550 & 556 \\
\hline $3 \mathrm{~A}$ & Sentences & 0 & 626 & 613 & 624 & 631 \\
\hline $3 B$ & Sentences & 0 & 587 & 597 & - & - \\
\hline $3 \mathrm{C}$ & Sentences & 0 & 580 & 602 & - & - \\
\hline $4 \mathrm{~A}$ & Sentences & 0 & 622 & 618 & 623 & 622 \\
\hline 4B & Sentences & 0 & 579 & 586 & 588 & 580 \\
\hline
\end{tabular}

Mean reaction times (in milliseconds, from target onset) for lexical decisions to visual target words in each priming condition.

Table 2

Associative priming results, Experiments 1, 3, and 4: Error rates

\begin{tabular}{|c|c|c|c|c|c|c|}
\hline \multirow[t]{2}{*}{ Experiment } & \multirow[t]{2}{*}{$\begin{array}{l}\text { Auditory } \\
\text { materials }\end{array}$} & \multirow[t]{2}{*}{$\begin{array}{l}\text { Inter stimulus } \\
\text { interval }\end{array}$} & \multicolumn{2}{|c|}{$\begin{array}{l}\text { Non-embedded prime } \\
\text { Prime-target relationship } \\
\end{array}$} & \multicolumn{2}{|c|}{$\begin{array}{l}\text { Embedded prime } \\
\text { Prime-target relationship }\end{array}$} \\
\hline & & & $\begin{array}{l}\text { Related } \\
\text { date-time }\end{array}$ & $\begin{array}{l}\text { Unrelated } \\
\text { come-time }\end{array}$ & $\begin{array}{l}\text { Related } \\
\text { sedate-time }\end{array}$ & $\begin{array}{l}\text { Unrelated } \\
\text { succumb-time }\end{array}$ \\
\hline \multirow[t]{3}{*}{$1 \mathrm{~A}$} & Isolated words & 0 & 1.2 & 3.9 & 3.1 & 3.1 \\
\hline & & 500 & 1.2 & 2.3 & 3.5 & 2.3 \\
\hline & & Combined & 1.2 & 3.1 & 3.3 & 2.7 \\
\hline \multirow[t]{3}{*}{ 1B } & Sentences & 0 & 1.6 & 1.6 & 1.6 & 2.3 \\
\hline & & 500 & 2.3 & 1.2 & 2.3 & 1.2 \\
\hline & & Combined & 2.0 & 1.4 & 2.0 & 1.8 \\
\hline $3 \mathrm{~A}$ & Sentences & 0 & 0.8 & 2.3 & 1.2 & 2.0 \\
\hline $3 \mathrm{~B}$ & Sentences & 0 & 0.8 & 2.5 & - & - \\
\hline $3 \mathrm{C}$ & Sentences & 0 & 1.4 & 3.9 & - & - \\
\hline $4 \mathrm{~A}$ & Sentences & 0 & 0.8 & 2.0 & 1.2 & 1.2 \\
\hline 4B & Sentences & 0 & 1.6 & 2.0 & 1.6 & 1.6 \\
\hline
\end{tabular}

Mean percentage error rates for lexical decision to visual target words in each priming condition.

Responses to targets were, on average, $26 \mathrm{~ms}$ faster after non-embedded primes than after embedded primes $(F 1(1,56)=24.39, p<.0001 ; F 2(1,31)=9.38, p<.005)$. There was, however, a significant interaction between relatedness and embedding $(F 1(1,56)=8.68$, $p<.005 ; F 2(1,31)=5.67, p<.05)$, reflecting the fact that the relatedness effect was much larger for the non-embedded words (mean difference: $39 \mathrm{~ms}$ ) than for the words embedded in the bisyllabic carriers (mean difference: $8 \mathrm{~ms}$ ). Sub-analyses showed that the relatedness effect was highly significant for the non-embedded words $(F 1(1,56)=32.51, p<.0001$; $F 2(1,31)=19.24, p<.0001)$, but not for the embedded words $(F 1(1,56)=1.00, p>.1$; $F 2<1)$. 
Responses when there was an ISI of $500 \mathrm{~ms}$ were somewhat faster than those when there was an ISI of $0 \mathrm{~ms}$. This effect of ISI was significant by items $(F 2(1,31)=56.53, p<.0001)$ but not by subjects $(F 1(1,56)=2.06, p>.1)$. Note that the discrepancy between the two analyses is a consequence of the fact that ISI is a between-subjects factor which appears as a within-items factor in the items analysis. Non-significant differences between subject groups can therefore produce significant effects in the items analysis. The only other significant effects were two three-way interactions involving the factor representing groups of subjects who received the four different lists. There were interactions between groups, ISI and relatedness $(F 1(3,56)=3.65, p<.02)$, and between groups, embedding and relatedness $(F 1(3,56)=3.60, p<.02)$. In the error analysis the effect of relatedness was not significant $\left(F_{\mathrm{S}}<1\right)$. The only significant effect in the errors was an interaction between groups and ISI $(F 1(3,56)=3.42, p<.05)$.

\subsubsection{Discussion}

A robust priming effect was found for targets preceded by monosyllabic words with which they were associatively related (e.g., date-time), but there was no evidence of priming from the same words to the same targets when the monosyllabic words were embedded as the second syllable of bisyllabic primes (e.g., sedate-time). This result contrasts with those from the studies by Isel and Bacri (1999) and Vroomen and de Gelder (1997), both of which tested priming with isolated words, and with those from the Shillcock (1990) study, which used words in sentences as primes. The results of Experiment $1 \mathrm{~A}$ alone do not allow us to determine whether our failure to observe embedded word priming is due to our use of isolated word primes (cf. the contrast with the Shillcock study, which used very similar English materials), or our use of English materials (cf. the contrast with the studies in French and Dutch by Isel and Bacri and by Vroomen and de Gelder, respectively). But note that the present results are in fact consistent with those from Gow and Gordon (1995), who failed to observe priming from words in sentences such as tulips to kiss, an associate of lips.

Experiment 1B was therefore an attempt to relate the findings of Experiment $1 \mathrm{~A}$ to the other literature on the activation of embedded words. The primes used in Experiment 1A were placed in sentence contexts. It is important to note, however, that the results with non-embedded primes in Experiment 1A validate our materials: The associative relationships between the monosyllabic words and their related targets are strong enough to produce a significant priming effect. That is, the failure to find an effect with the embeddedword primes is not because the associations between the embedded words and their related targets were too weak or too variable.

\subsection{Experiment 1B: Prime words in sentences}

\subsubsection{Method}

2.2.1.1. Materials and design. The primes from Experiment 1A (monosyllabic words, bisyllabic carriers with embedded words, and fillers) were placed in sentence contexts. Those for the experimental trials are listed in Appendix B. Each of the sentences was constructed such that context before the critical prime word was not predictive of the prime. The experimental sentences were built in pairs, one for each pair of monosyllabic and bisyllabic items, using as much overlapping material as possible, and such that the embedded words in the bisyllabic primes appeared the same number of syllables into their sentences as the 
non-embedded words in the matched sentences. This could often be achieved by substituting the first syllable of the bisyllabic word with a function word consisting of a reduced syllable (e.g., the sentence pair "They planned sedate and placid meals with the ambassador"; "They planned a date and place to meet with the ambassador"). The visual targets were the same as those used in Experiment 1A. Practice trials were generated by constructing an additional 10 prime-target pairs. These primes, along with the 10 from Experiment $1 \mathrm{~A}$, were placed in sentence contexts to produce 20 practice trials.

2.2.1.2. Procedure. The sentences were recorded by a male native speaker who was a trained phonetician. This was not the same speaker who recorded the stimuli for Experiment $1 \mathrm{~A}$. He read each of the sentences aloud in a clear and natural way to convey the meaning, using neutral intonation (i.e., in a matter-of-fact fashion, with no contrastive accents). He also attempted to match the prosodic contours of each of the pairs of experimental sentences. The auditory stimuli were then prepared in the same way as in Experiment 1A.

The equipment and basic procedure were identical to Experiment 1A. Note, however, that the sentence materials were played in their entirety; they did not terminate at the offset of the prime word. Participants thus heard portions of the post-prime parts of the sentences as they made their lexical decisions to the visual targets. In contrast to Experiment 1A, the materials were split into two blocks. The order of presentation of the two blocks was counterbalanced across participants. Within each block there was a single randomization of the materials in each of the four lists. That is, the matched embedded/non-embedded sentence pairs and all of the fillers appeared in the same order in each block.

Instructions to participants were the same as in Experiment 1A, with the exception that they were told that they would be asked questions about the sentences afterwards rather than being told to repeat the primes. At the end of the experiment participants were shown twenty written sentences, half of which had appeared in the experiment. They were instructed to indicate whether they had heard the sentences in the experiment.

2.2.1.3. Participants. The listeners in the $0 \mathrm{~ms}$ ISI condition were 44 students from St. John's College, Cambridge, and Churchill College, Cambridge. Data from 12 participants were rejected because they scored less than $70 \%$ correct on the recognition test. In the $500 \mathrm{~ms}$ ISI condition there were 47 participants, who were members of Downing College, Cambridge or of the MRC Cognition and Brain Sciences Unit volunteer panel. The data from fifteen participants were rejected because they scored less than $70 \%$ correct on the recognition test.

\subsubsection{Results}

The mean recognition scores for the participants who passed the recognition test were $79 \%$ for the $0 \mathrm{~ms}$ ISI condition and $80 \%$ for the $500 \mathrm{~ms}$ ISI condition. The lexical decision results from Experiment $1 \mathrm{~B}$ are shown in Tables 1 and 2. In contrast to Experiment $1 \mathrm{~A}$, the main effect of relatedness was not significant in either the latency $(F 1(1,56)=2.75, p>.1$; $F 2(1,31)=1.19, p>.2)$ or the error analysis $(F \mathrm{~s}<1)$. Responses to related targets were thus not significantly faster than responses to unrelated targets, whether the primes were embedded or not. Furthermore, there was no effect of embedding (latencies and errors, $F \mathrm{~s}<1)$, and ISI was significant only in the items analysis of latencies $(F 1<1$; $F 2(1,31)=4.33, p<.05)$. The only other significant results involved subject groups. 
In latencies there was a three-way interaction between groups, ISI and relatedness $(F(3,56)=3.18, p<.05)$ and a four-way interaction between groups, ISI, relatedness and embedding $(F(3,56)=3.57, p<.02)$. In the error analysis there was a two-way interaction between groups and relatedness $(F 1(3,56)=2.77, p<.05)$.

\subsubsection{Discussion}

Experiment 1B produced a non-significant priming effect of about $8 \mathrm{~ms}$, and no interaction between priming and embedding. The experiment thus failed to replicate Shillcock (1990), despite the overall similarity of the two studies. More strikingly, there was also no evidence of associative priming for the non-embedded words. This stands in contrast to the results of many previous studies using this paradigm, discussed in the introduction, which have found associative priming when the primes were words which the speaker intended (i.e., when they were not embedded words).

As we noted in the introduction, there are two previous studies that also failed to find cross-modal associative priming effects with non-embedded words in sentences. Both Tabossi (1988a) and Williams (1988) found no priming when the target words were not related to the overall meaning of the rest of the sentence containing prime words. Williams did, however, find associative priming from the same prime words presented in lists of unrelated items. The straightforward implication of these findings is that cross-modal associative priming is not sensitive to automatic lexical activation. Words must be semantically activated to permit listeners to construct a semantic interpretation of the sentence, but this activation need not produce priming.

Experiments $1 \mathrm{~A}$ and $1 \mathrm{~B}$ produced the same pattern of priming as reported by Williams (1988). Words that failed to produce priming in sentences did produce priming when presented in isolation. It is thus possible that the non-embedded words in Experiment 1A produced facilitation of target responses because they were the only available context, while the same words in Experiment 1B did not produce facilitation because the meanings of the sentences up to and including the primes were not strongly associated with the meanings of the targets. This account might also explain the results for the embedded words, not only those in sentences (where again the meaning of the sentence fragments would not be strongly associated with the meanings of the targets) but also in isolation. If the "effective context" for the embedded word condition in Experiment 1A was the meaning of the bisyllabic carrier words, then again no priming would be predicted based on the associations of the embedded words.

One way of interpreting this effective context explanation is that the task of attending to the sentence level interpretation requires the listener to inhibit word-level representations. This would be consistent with the arguments of Marí-Beffa et al. (2000). Another way of interpreting this explanation is in terms of compound cueing theory (Ratcliff \& McKoon, 1988). Sentences and individual words lead to different compound cues, and may therefore produce quite different patterns of priming. But whatever the exact explanation for variations in effective context might be, a clear prediction of this account is that it ought to be possible to induce an associative priming effect with sentential materials. If a manipulation can cause the meaning of the prime to be part of the target's effective context, then associative priming should result. Experiments 3 and 4 addressed this issue, and hence also examined the apparent discrepancy between the results of Experiment $1 \mathrm{~B}$ and those from the previous literature showing associative facilitation in sentence contexts. 
All these following experiments use only a 0-ms ISI. In Experiment 1 the ISI manipulation made no contribution to the results (it only interacted with the group factor). Although ISI can provide useful information on the decay of associative priming when such priming occurs (e.g., Swinney, 1979), the prerequisites for its usefulness were not met in our experiment since no priming effects appeared at all.

The next two experiments used identity priming rather than associative priming. Although identity priming might not be sensitive to conceptual activation, it should be sensitive to activation of phonological representations. Experiment 2 was therefore an attempt to tap into the activation of the phonological representations of both embedded and nonembedded words. This comparison should be informative about whether there is a distinction between type and token representations of phonological form. Specifically, if identity priming reflects the activation of the token representations which enter into lexical competition, there should be facilitatory priming from tokens which win the competition (the non-embedded words) and inhibitory priming from tokens which lose the competition (the embedded words). Furthermore, the comparison of the pattern of identity priming results with the previous associative priming data should be informative about the relationship between phonological and semantic levels of lexical representation. The extent to which the pattern of identity priming mirrors what was found with associative priming should reflect the independence and separability of phonological and conceptual representations in the speech comprehension system. Experiments $2 \mathrm{~A}$ and $2 \mathrm{~B}$ therefore employed the same recordings of words and sentences used in Experiments $1 \mathrm{~A}$ and $1 \mathrm{~B}$.

\section{Experiment 2: Identity priming}

\subsection{Experiment 2A: Prime words in isolation}

\subsubsection{Method}

Experiment 2A used the same materials and general procedure as Experiment $1 \mathrm{~A}$, but used identity priming rather than associative priming. As a consequence of the change from associative to identity priming, the words in unrelated pairs appeared both as auditory primes and visual targets in the same experimental list. For example, the unrelated pair come-date appeared in the same list as date-come. This was also true of the unrelated embedded pairs (e.g., sedate-come and succumb-date appeared in the same list). The experimental materials were therefore split into two blocks such that only one member of a repeated pair appeared in any one block. Half of the participants received the blocks in one order, and the other half received the other order. To ensure that form overlap itself was not a reliable cue to whether the target was a word or not, we also altered 24 non-word filler trials so that the non-words had phonological overlap with the auditory primes. For example, swing-dactor became swing-swib, session-mip became session-sessiom and regardlittuce became regard-gart. Also, filler trials that had consisted of related bisyllabic words (concern-worry) became identity primed bisyllabic fillers (concern-concern), so that identity targets were not always monosyllabic. We also ensured that both monosyllabic and bisyllabic primes were as likely to be followed by a word as by a non-word. ISI was always 0 ms.

3.1.1.1. Participants. There were 32 participants from Girton College, Cambridge, Fitzwilliam College, Cambridge, and the MRC Cognition and Brain Sciences Unit volunteer panel. 


\subsubsection{Results}

As in Experiment 1A, participants were very accurate at repeating the prime words; they made errors, overall, on fewer than $2 \%$ of experimental trials. In both this experiment and Experiment $2 \mathrm{~B}$ there were no significant effects or interactions involving the order in which the unrelated pairs appeared. Order was therefore not included as a factor in any of the analyses reported. The results from Experiment $2 \mathrm{~A}$ are shown in Table 3. As in Experiment 1A, responses to related targets were substantially faster than those to unrelated targets (mean difference: $61 \mathrm{~ms} ; F 1(1,28)=32.65, p<.0001 ; F 2(1,31)=15.23, p<.0005)$. There was, however, a significant interaction between relatedness and embedding $(F 1(1,28)=26.61$, $p<.0001 ; F 2(1,31)=21.01, p<.0001)$. The priming effect was $136 \mathrm{~ms}$ for monosyllabic, non-embedded words $(F 1(1,28)=55.14, p<.0001 ; F 2(1,31)=79.34, p<.0001)$, but $-15 \mathrm{~ms}$ for embedded words $\left(F_{\mathrm{s}}<1\right)$. As a consequence of the large priming effect for non-embedded words, responses to targets following these words were faster overall than responses to targets following embedded words (mean difference: $80 \mathrm{~ms} ; F 1(1,28)=56.90, p<.0001$; $F 2(1,31)=33.78, p<.0001)$. There was also an interaction between embedding and groups $(F 1(3,28)=3.15, p<.05)$.

In the error analysis, there was no significant effect of relatedness $(F \mathrm{~s}<1)$, but there was an interaction between relatedness and embedding $(F 1(1,28)=5.77, \quad p<.05$; $F 2(1,31)=4.58, p<.05)$. There were fewer errors to related targets following non-embedded words, and more to related words following embedded words. However, relatedness was not significant in the separate analyses of non-embedded words $(F 1(1,28)=2.15, p>.1$; $F 2(1,31)=1.63, p>.2)$ or embedded words $(F 1(1,28)=3.57, p>.05 ; F 2(1,31)=3.49$, $p>.05)$. Relatedness also interacted with groups $(F 1(3,28)=4.51, p<.05)$. In line with the latency analysis, there were significantly fewer errors for targets following monosyllabic words than embedded words $(F 1(1,28)=8.40, p<.01 ; F 2(1,31)=5.02, p<.05)$.

\subsubsection{Discussion}

The general pattern of data from Experiment $2 \mathrm{~A}$ is very similar to that observed in Experiment 1A. There was facilitation for non-embedded words, but not for embedded words. In fact, there was even a hint that targets related to embedded words were inhibited. This is in line with previous identity priming data. As mentioned in the introduction, trombone-bone pairs in Marslen-Wilson et al. (1994) produced a statistically non-significant inhibitory effect of $12 \mathrm{~ms}$. Shatzman (2006) observed statistically significant inhibition

Table 3

Identity priming results, Experiment 2 (inter stimulus interval $=0 \mathrm{~ms}$ )

\begin{tabular}{|c|c|c|c|c|c|c|}
\hline \multirow[t]{4}{*}{ Experiment } & \multirow{4}{*}{$\begin{array}{l}\text { Auditory } \\
\text { materials }\end{array}$} & \multirow[t]{4}{*}{ Measure } & \multirow{2}{*}{\multicolumn{2}{|c|}{$\begin{array}{l}\text { Non-embedded Prime } \\
\text { Prime-target relationship }\end{array}$}} & \multirow{2}{*}{\multicolumn{2}{|c|}{$\begin{array}{l}\text { Embedded prime } \\
\text { Prime-target relationship }\end{array}$}} \\
\hline & & & & & & \\
\hline & & & Related & Unrelated & Related & Unrelated \\
\hline & & & date-date & come-date & sedate-date & succumb-date \\
\hline \multirow[t]{2}{*}{$2 \mathrm{~A}$} & Isolated words & $\mathrm{RT}$ & 605 & 741 & 760 & 745 \\
\hline & & Error & 1.2 & 2.7 & 7.4 & 3.9 \\
\hline \multirow[t]{2}{*}{$2 \mathrm{~B}$} & Sentences & $\mathrm{RT}$ & 587 & 634 & 682 & 626 \\
\hline & & Error & 0.8 & 4.7 & 3.5 & 5.1 \\
\hline
\end{tabular}

Mean reaction times (in milliseconds, from target onset) and mean percentage error rates for lexical decisions to visual target words in each priming condition. 
(an effect of $39 \mathrm{~ms}$ with Dutch item pairs equivalent to trombone-bone). Experiment 2B examined identity priming in sentences.

\subsection{Experiment $2 \mathrm{~B}$ : Prime words in sentences}

\subsubsection{Method}

Experiment 2B used the same sentence recordings used in Experiment 1B, and the visual targets used in Experiment 2A. In this experiment, half of the repeated words (e.g., datecome and come-date) always appeared in one order (visual target before auditory prime, or vice versa) and half always appeared in the other order. Also, instead of informing participants that they would be asked questions about the sentences, we required participants to repeat some of the sentences aloud immediately after they heard them. All experimental trials and four filler trials with non-word targets were followed by the prompt "Please repeat the sentence." Participants' repetitions were recorded on audio tape. Repetitions were considered to be acceptable if they included a reasonable paraphrase of the experimental sentence at least up to the prime word and the prime word itself. The criterion for inclusion in this experiment (and all subsequent experiments which used sentence materials) was that a participant make no more than six errors in repetition. The implications of this procedural change from Experiment 1B will be addressed in a later experiment.

\subsubsection{Participants. Thirty-two students from Robinson College, Cambridge, participated.}

\subsubsection{Results}

The results from Experiment 2B are shown in Table 3. Overall, responses to related targets were no faster than responses to unrelated targets $\left(F_{\mathrm{S}}<1\right)$. However, there was a significant interaction between relatedness and embedding $(F 1(1,28)=46.27, p<.0001$; $F 2(1,31)=23.21, p<.0001)$. As in the case of identity priming with isolated words, there was a significant facilitatory effect of relatedness for targets following non-embedded words (mean difference: $47 \mathrm{~ms} ; F 1(1,28)=21.38, p<.0001 ; F 2(1,31)=10.53, p<.005)$. However, in contrast to the previous experiment, the inhibitory effect observed with embedded primes was also significant (mean difference: $-56 \mathrm{~ms} ; \quad F 1(1,28)=15.65$, $p<.0005 ; F 2(1,31)=9.18, p<.005)$. Although response times were little different to unrelated targets following non-embedded or embedded primes, the pattern of facilitation and inhibition for related primes meant that responses to targets following non-embedded primes were faster overall $(F 1(1,28)=25.08, p<.0001 ; F 2(1,31)=16.88, p<.0005)$.

In the error analysis there was a significant overall effect of relatedness $(F 1(1,28)=4.43$, $p<.05 ; F 2(1,31)=6.36, p<.05)$. Priming was facilitatory for both non-embedded $(F 1(1,28)=4.55, p<.05 ; F 2(1,31)=8.91, p<.01)$ and embedded words, but the effect for embedded words was not significant $(F 1<1 ; F 2(1,31)=1.15, p>.2)$. The only other significant result was an interaction of groups and embedding $(F 1(3,28)=6.86, p<.005)$.

\subsubsection{Discussion}

In contrast to associative priming, identity priming in sentences produced significant facilitation following non-embedded words. In this respect, the data are similar to the results of both the identity priming and associative priming experiments with isolated words. However, in addition to a facilitatory effect with non-embedded monosyllables, 
there was a substantial inhibitory effect with embedded words. This result is consistent with one of the possibilities discussed earlier. Embedded words are initially activated, but then they must be suppressed, and this results in negative priming. Note that it must have been the case that embedded words are activated at some point, or else they would not be inhibited relative to unrelated words. If embedded words were never activated, primes with embedded words would have had the same effect as unrelated primes.

One possible alternative account for the inhibition observed with embedded words is that it reflects a checking strategy. Participants could perhaps have noticed that the targets on related trials (e.g., date after hearing sedate) corresponded to a string that they had just heard, and that this spoken sequence was not the same word. This could have delayed positive lexical decision latencies relative to unrelated trials. There are several reasons to disfavor this account. First, it seems unlikely that participants would adopt such a checking strategy, since it would be of no benefit to them in performing the lexical decision task: There were as many trials where primes were embedded related words as where they were non-embedded related words, and related trials constituted only $20 \%$ of all trials. Second, this account predicts that the inhibitory effect ought to be stronger with isolated primes than in sentences (because it should be easier to notice the overlap with isolated words). But a stronger effect was found in sentences than with isolated words.

The pattern of results in Experiment 2 is consistent with the operation of Shortlist (Norris, 1994), where the initial perceptual match between the input and a lexical entry activates a token representation of that word's phonological form. This token representation then enters into the competition process and will be inhibited when it loses the competition to the longer embedding word (see Fig. 1). Suppression of that lexical token representation will then inhibit subsequent identification of a visually presented instance of that word.

The results of Experiments 1 and 2 present a quite straightforward picture. Monosyllabic words produce a facilitatory effect of identity priming, whether those words appear in isolation or in sentences. Identity priming from embedded words tends to be inhibitory, although only significantly so for sentences. In contrast, associative priming was only found with isolated monosyllabic words. There was no sign of associative priming in sentences, and no sign of inhibition with embedded words. Although this result is consistent with Williams (1988), other studies have found associative priming from words in sentences contexts. Associative priming in sentence contexts has been found with complete words (e.g., Swinney, 1979; Tabossi, 1996), with embedded words (e.g., Shillcock, 1990) and with word fragments (e.g., Zwitserlood, 1989). To address this apparent discrepancy between our results and those of these other studies, we conducted a series of six experiments (Experiments $3 \mathrm{~A}-\mathrm{C}$ and $4 \mathrm{~A}-\mathrm{C}$ ) that attempt to establish conditions that will produce cross-modal associative priming using stimuli based on those used in Experiment $1 \mathrm{~B}$. These are reported in the next section.

Experiment 3 examines three design factors that might have mitigated against finding priming in Experiment 1B. One possibility was that the recognition task used in Experiment $1 \mathrm{~B}$ might not have induced listeners to attend carefully to the sentences. Experiment $3 \mathrm{~A}$ therefore replicated the $0 \mathrm{~ms}$ ISI conditions of Experiment $1 \mathrm{~B}$, but with the secondary task used in Experiment 2B. Listeners were required to repeat all of the experimental sentences and a few filler sentences verbatim, immediately after they heard each of them.

A second possibility was that the cross-modal associative priming effects observed in other studies may have been due, at least in part, to strategic factors. Participants may have become aware of the relationships between primes and targets in these experiments. 
There are a number of ways in which listeners' attention could be drawn to prime-target relationships. For example, some studies have found priming when only sentence fragments were presented, that is, when the auditory material terminated with the critical word or word fragment (Tabossi et al., 2000; Zwitserlood, 1989; Zwitserlood \& Schriefers, 1995). When the last word the listener hears is related to the visual target, this is likely to draw attention to the association between prime and target, and to disrupt the interpretation of the sentence. The priming effect could thus be caused by listeners explicitly checking for these associations.

In Experiments 3B and 3C, we therefore examined two factors that might draw participants' attention to the relation between primes and targets. In Experiment 3B we varied the proportion of related trials. In our previous experiments, half of the related experimental trials had embedded prime words. Participants may be less likely to become aware of the relationships between these primes and their targets than of the relationships between the non-embedded primes and their targets. To increase the likelihood that subjects would become aware of the prime-target relationships, we removed the embedded word primes from the experiment. Experiment 3B was thus a repetition of Experiment 3A, but using only the monosyllabic, non-embedded primes.

In Experiment 3C we took a more extreme measure to try and draw participants' attention to the relationship between prime and target. As noted above, experiments where the speech signal terminates after the prime (as in, e.g., Zwitserlood, 1989), have fairly consistently found associative priming. Experiment $3 \mathrm{C}$ was therefore identical to $3 \mathrm{~B}$, but with the sentences truncated at the end of the prime.

\section{Experiments 3A-C: Associative priming, procedural manipulations}

\subsection{Method}

All three versions of this experiment were identical in terms of procedure to the $0 \mathrm{~ms}$ ISI condition of Experiment 1B except that participants were required to repeat sentences as in Experiment 2B. In Experiment 3A, this procedural change was the only difference from the $0 \mathrm{~ms}$ ISI condition of Experiment 1B. In Experiment 3B, however, participants heard only the versions of the experimental sentences in which the prime was a non-embedded word. Consequently the counter-balancing required only two presentation lists, in contrast to the four lists used in the previous experiments. For sentences in the practice session in which the visual target was related to an embedded word, the target word was replaced with one related to the meaning of the bisyllabic carrier word. The materials and procedure were otherwise identical to Experiment 3A.

Experiment $3 \mathrm{C}$ was identical to Experiment $3 \mathrm{~B}$ except that sentences were truncated at the end of the prime. To avoid audible clicks, the audio signal was ramped down to zero over the $50 \mathrm{~ms}$ following the end of the prime. The truncated versions of the stimuli were pretested to check whether this led to any difficulties in recognizing the prime. Five listeners from the MRC Cognition and Brain Sciences Unit volunteer panel, who did not participate in any of the main experiments, were presented with the truncated sentences and asked to write down the last word they heard. All of the experimental prime words were always reported correctly except one (crease was heard by one listener as increase). Truncation therefore did not induce perceptual distortions at the offset of the experimental primes. Four filler primes, however, tended to be misheard. New versions of these fillers 
were therefore made in which the truncation point was shifted to a little later in time, thus improving prime perceptiblity. Minimal changes were made to instructions and procedures to adjust for the shorter auditory stimuli; in particular, the instructions were changed to refer to "the beginnings of sentences" and stated that, when required, participants should "say out aloud all that you heard of the last sentence as accurately as you can." These oral responses were recorded.

\subsubsection{Participants}

Participants in Experiment 3A were 33 members of the MRC Cognition and Brain Sciences Unit volunteer panel. One participant's data were excluded from the analysis because the participant failed the repetition test. In Experiment 3B, participants were 32 students from St. Catherine's College, Cambridge. The 32 participants in Experiment 3C were also from the MRC Cognition and Brain Sciences Unit volunteer panel.

\subsection{Results}

The results from Experiment 3 are shown in Tables 1 and 2. In common with Experiment $1 \mathrm{~B}$, there were no fully significant priming effects in the experiments using complete sentences. In Experiment $3 \mathrm{~A}$, there was no relatedness effect in either latencies $(F \mathrm{~S}<1)$ or errors $(F 1(1,28)=1.68, p>.2 ; F 2(1,31)=3.21, p>.05)$, and no other effects were significant. The move from a recognition task to a repetition task actually decreased the priming effect slightly, from 8 to $-10 \mathrm{~ms}$. In Experiment 3B, the effect of relatedness (for the non-embedded primes only) was facilitatory $(10 \mathrm{~ms})$, but again was not significant in the latency analysis $(F 1(1,30)=1.58, p>.20 ; F 2<1)$. Although there were fewer errors to related than unrelated targets, this difference was significant only in the subjects analysis $(F 1(1,30)=4.62, p<.05 ; F 2(1,31)=3.83, p>.05)$.

In contrast to Experiments $3 \mathrm{~A}$ and $3 \mathrm{~B}$, there was a $22-\mathrm{ms}$ priming effect in Experiment $3 \mathrm{C}$ that was significant in the subjects analysis $(F 1(1,30)=6.83, p<.05)$, although it just missed being significant in the items analysis $(F 2(1,31)=4.04, p=.053)$. Related items were responded to significantly more accurately than unrelated items $(F 1(1,30)=6.91, p<.05$; $F 2(1,31)=4.86, p<.05)$. The only other significant results were interactions between priming and groups in both the latency $(F 1(1,30)=6.83, p<.05)$ and in the error $(F 1(1,30)=6.91, p<.05)$ analyses.

We also conducted an analysis comparing Experiment 3B with Experiment 3C. While the overall effect of priming in the combined analysis was significant $(F 1(1,60)=7.60$, $p<.01 ; F 2(1,31)=6.15, p<.02)$ there was no significant interaction between priming and experiment $(F 1(1,60)=1.03, p<.5 ; F 2(1,31)<1)$.

\subsection{Discussion}

The results of all of the associative priming experiments so far are consistent with the effective context hypothesis: It is only when the auditory stimuli consist of the non-embedded primes in isolation (i.e., as in Experiment 1A) or at the ends of truncated sentences (as in Experiment 3C) that a statistically significant priming effect emerges. Changing the secondary task (Experiment 1B versus 3A) failed to induce a priming effect for either embedded or non-embedded primes. Likewise, increasing the proportion of clearly related trials produced a non-significant priming effect for non-embedded primes of only $10 \mathrm{~ms}$ 
(Experiment 3B). Even when more than half of the word targets were associatively related to their primes, participants failed to use those associations to bias their lexical decision performance. Experiment 3C demonstrates that the stimuli from Experiment 3B produce a significant priming effect when presentation of the sentence is terminated at the offset of the prime. This is consistent with the conclusions we drew from our review of the priming literature where we noted that many of the studies that had reported cross-modal associative priming had stopped presentation of the sentences immediately after the prime word. We suggested that this manipulation was likely to increase the prominence of the prime word in the sentence.

These results make one further point. It is conceivable that part of the reason for our failure to obtain priming effects might be limitations on the perceptibility of the prime words (although any such problem would need to apply to both of our speakers). For example, it might be the case that isolated words were articulated more clearly than the same words in sentences and thus isolated words were more effective primes (cf. Boothroyd \& Nittrouer, 1988; Miller, Heise, \& Lichten, 1951). However, Experiment 3C shows that exactly the same acoustic tokens of the words can produce priming when the sentence is truncated. Whatever the reason for our failure to obtain associative priming in Experiments $3 \mathrm{~A}$ and $3 \mathrm{~B}$, it cannot be attributable to problems with the acoustic realization of the words themselves, or we would not have found priming here either.

Note that although there is no significant interaction between the size of the priming effect and whether or not the sentence was truncated, this does not affect the point we wish to make here. There is no reason to expect that a significant difference should always appear in the size of the priming effect in complete and truncated sentences. This manipulation is just one of a number of factors that may increase the likelihood of observing priming. The important finding is that when we model our experiment after the design that has most commonly produced a priming effect, we also observe priming.

The results from the secondary tasks in Experiments $1 \mathrm{~B}$ and $3 \mathrm{~A}$ and $3 \mathrm{~B}$ show that participants were attending to the sentences, and recognizing the words of those sentences. Presumably, they were also constructing interpretations of those utterances. It therefore appears that the effective context explanation for these results may be correct. If the effective context is sentence meaning, then there will be no signs of priming if the meaning of the prime word is not yet being incorporated into the interpretation of the sentence. This account suggests that if listeners could be encouraged to incorporate a richer word meaning representation into the representation of the sentence, associative priming might emerge. We tested this prediction in Experiment 4 . We attempted to encourage listeners to process the primes more deeply. We predicted the appearance of associative priming if listeners were to involve the meaning of the primes in their sentential interpretations.

In Experiment 4B, we modified the sentences by providing semantically richer contexts for the prime words. One way to encourage greater depth of processing on particular words in sentence contexts is to make them the semantic focus of their carrier sentences (Blutner \& Sommer, 1988; Cutler \& Fodor, 1979). Blutner and Sommer, for example, used cross-modal priming to study lexical ambiguity in the context of manipulations of sentence focus. Their experiment was similar to the Swinney (1979) cross-modal priming study, but they presented two sentences on each trial. For example, the critical sentence "The scenery with the mast disappointed the visitors of the gallery" (their English translation of one of their German sentences, where the German word Mast is lexically ambiguous, meaning 
either "telegraph pole" or "food;" the target was presented after Mast), could be preceded with either "Which scenery disappointed the visitors?" or "Which visitors did the scenery disappoint?" With an ISI of $0 \mathrm{~ms}$ they found priming to both readings of the ambiguous words, but only when those words were focused. At a 350-ms ISI, the biased words produced priming, regardless of whether or not they were focused, and the alternative readings never did.

It was not possible to construct focus-biasing lead-in sentences for the sentences used in Experiments 1B, therefore the sentences themselves were manipulated instead. The original sentences were designed to be semantically neutral. As a consequence they tended to have abstract or non-specific referents, particularly in the early (pre-prime) sections. In the majority of cases the subject of the sentence was a pronoun (e.g., "They planned a date...," "He gave up the seat..."; see Appendix B). We provided richer semantic contexts by replacing these pronouns with nouns, by marking those nouns with adjectives, or by adding adverbial qualifiers (e.g., "The cultural delegation planned a date...," "The businessman immediately gave up the seat..."; see Appendix C). We hoped that these contexts would encourage participants to process the sentences, and, in particular, the primes more deeply. If this manipulation were to make the meanings of the primes part of the effective contexts of the targets, associative priming would result.

As the speaker who recorded the original sentence materials was no longer available, we had to use a different speaker. This raised the possibility that, if we were to find priming with the new materials, this could be attributable to differences between the two speakers rather than to differences in the sentence contexts. Given the elusive nature of cross-modal associative priming in sentence contexts, the possibility must exist that the results could be influenced by characteristics of the speaker. We therefore decided to begin by replicating Experiment $3 \mathrm{~A}$ with recordings made by a new speaker. Recording conditions and stimulus preparation were the same as in Experiment 1B. The new speaker was a male native speaker of British English (the third author), who, like the original speaker, produced the sentences using neutral intonation contours.

\section{Experiment 4: Associative priming}

\subsection{Experiment 4A: Replication}

\subsubsection{Method}

New recordings were made of the sentences used in Experiments $1 \mathrm{~B}, 2 \mathrm{~B}$ and 3. The procedure was as in Experiment 3A. Participants were 32 students from St. John's College, Cambridge.

\subsubsection{Results}

The results are shown in Tables 1 and 2. The overall priming effect was once again slightly inhibitory $(-3 \mathrm{~ms})$ and was not significant in either the latency or error analyses $(F \mathrm{~s}<1)$. No other effects were significant.

\subsubsection{Discussion}

The results of Experiment $4 \mathrm{~A}$ replicate those of Experiment $3 \mathrm{~A}$. The absence of priming in Experiments 1B, 3A, and 3B therefore cannot readily be attributable to any peculiarities of the speaker. 


\subsection{Experiment 4B: Rich context}

\subsubsection{Method}

The experimental sentences were revised such that their pre-prime portions provided a richer semantic context (see Appendix C). The sentence pairs were still matched with respect to the number of syllables before the (embedded or non-embedded) prime. Nine of the filler sentences were also revised to match the style of the new experimental sentences. These materials were recorded by the speaker used in Experiment $4 \mathrm{~A}$. The sentences were again produced with neutral intonation contours. The experiment was otherwise identical to Experiment $4 \mathrm{~A}$.

5.2.1.1. Participants. Thirty-three students, either from Girton College, Cambridge, or the MRC Cognition and Brain Sciences Unit volunteer panel, participated. The data from one participant, who failed the repetition test, were excluded.

\subsubsection{Results}

The results of Experiment 4B are shown in Tables 1 and 2. For non-embedded words, the priming effect was $7 \mathrm{~ms}$. For embedded words there was an inhibitory effect of $8 \mathrm{~ms}$. No effect of relatedness or embedding was significant in either latencies or errors (all $F_{\mathrm{S}}<1$ ). The interaction between relatedness and embedding was not significant in either the latency analysis $(F 1=1.31, p>.2 ; F 2<1)$ or in errors $(F \mathrm{~s}<1)$.

\subsubsection{Discussion}

The manipulation of sentence context clearly failed to produce a priming effect. There was again no associative priming, from either the monosyllabic words embedded in bisyllabic carriers or even the non-embedded versions of these words. Remember, however, that these non-embedded words did produce priming when they were spoken in isolation (Experiment 1A) and when the (neutral) sentences were truncated after the prime (Experiment $3 \mathrm{C}$ ). The associative relationships between primes and targets were therefore robust enough to produce priming under at least some circumstances. It is still possible that an even richer context (such as the long multi-clausal sentences used by Cutler, 1986, and Lucas, 1987) would have had greater influence.

In Experiment 4C, however, we made a different kind of attempt to demonstrate associative priming from non-embedded words in sentence contexts. We did so by manipulating the prosodic structure of the sentences. In all our experiments so far with sentence materials, the sentences had neutral intonation contours. Specifically, there were no contrastive accents marking particular words as being more salient than the other words in the sentences. This was done to match the sentences better (e.g., to avoid obvious prosodic differences between the sentences with embedded primes and those with non-embedded primes) and to avoid drawing the listeners' attention to (or away from) the prime words. But this may have had the effect of discouraging listeners from fully processing the meaning of the sentences. The matter-of-fact style of the speakers did not stimulate the listeners' interest in the content of the sentences (and note also that the secondary tasks could be completed satisfactorily with only a relatively shallow analysis of the sentences). It is possible that the lack of associative priming in Experiments 1B, 3A, 3B, 4A, and 4B may thus have resulted from shallow processing of the primes, which in turn was encouraged by the neutral prosody of the sentences. Note that this possibility is consistent with the effective 
context hypothesis: If the context for priming is a semantically shallow representation of a sentence fragment that does not involve the meaning of the prime to any significant extent, there should be no associative priming.

The sentences used in Experiment 4C therefore had non-neutral prosodic contours. Specifically, the sentences varied in the placement of contrastive accents. The non-embedded primes from the preceding experiments (e.g., date) were presented in two versions of the same sentence, one in which the prime received a contrastive accent ("He suggested that it was really the DATE of the election that mattered"), and one in which a later word in the sentence was accented ("He suggested that it was really the date of the ELECTION that mattered"). Note that it was not possible to find two contrastive accent locations in each of the sentence frames from Experiment 1B, nor in those from Experiment 4B. New sentences were therefore constructed for each of the non-embedded primes. The same targets as in the earlier experiments were used, however. Contrastive accent was chosen as the prosodic variable because it has semantic implications: A particular scenario is contrasted with an alternative possibility (e.g., in the first of the above examples, it is the DATE of the election that mattered, rather than some other aspect of the election, in the second, it is the date of the ELECTION, rather than some other date). Contrastive accent thus stimulates semantic analysis.

Two predictions about the effects of this manipulation were tested. One possible outcome was that associative priming would be found when the prime words were accented, but not when they were deaccented (i.e., when another word was accented). Accented words are processed differently from deaccented words (see Cutler, in press, Cutler, Dahan, \& van Donselaar, 1997, for reviews). For example, Cutler (1976) has shown that listeners use the prosodic contour preceding an accented word to predict where an accent will occur, and Akker and Cutler (2003) demonstrated that this prediction indeed serves the purpose of locating the semantic focus of the utterance. Furthermore, Dahan, Tanenhaus, and Chambers (2002) have shown that the discourse implications of an accented word (whether it is a given or a new entity) can be inferred very quickly, during the processing of the first syllable of the accented word. If accent thus encourages listeners to attend to the words in accented/focussed positions, and if discourse-level information about accented words can be rapidly retrieved, then it is possible that the meaning of accented words will be accessed quickly, and associative priming may then result. If deeper semantic analysis is limited to accented words, there should be no priming from deaccented primes. An alternative outcome, however, was that there would be a priming effect on both accented and deaccented primes. Such a finding would suggest that the presence of an accent anywhere in a sentence (or indeed of contrastive accents in the experiment as a whole) is sufficient to increase meaning-level processing of the sentences. Either of these outcomes, in contrast to the null effects with the complete versions of the prosodically neutral sentences in the previous experiments, would suggest that the prosodic structure of sentences has an important role to play in the way in which spoken sentences are processed.

\subsection{Experiment 4C: Contrastive accent}

\subsubsection{Method}

New sentences were constructed based on the non-embedded primes used previously. To increase the power of the experiment to detect associative priming we presented listeners with only the non-embedded primes, as in Experiment 3B. Each sentence was 
constructed such that a contrastive accent could be placed in two positions in that sentence, either the prime word or a word later in the sentence. These materials are listed in Appendix D. Some of the filler sentences were also revised to facilitate the placement of a contrastive accent in each of those sentences. Accent location in the filler sentences was varied such that, across the experiment as a whole, accents appeared in a variety of positions in the sentences, and were not always placed on words which were followed by a visual target. The procedure was otherwise identical to Experiment $4 \mathrm{~B}$. The sentences were recorded by the same speaker who recorded the materials for Experiments 4A and 4B.

\subsubsection{Participants. Thirty-two members of the MRC Cognition and Brain Sciences Unit volunteer panel participated.}

\subsubsection{Results}

The results from Experiment 4C are shown in Table 4. Two items were excluded from all analyses: those involving the prime-target pairs rock-hard and vat-tax. Due to an oversight, the rock sentence contained the word harder (see Appendix D). The tax set was matched to the hard set. Related words were responded to significantly faster than unrelated words (mean difference: $34 \mathrm{~ms} ; F 1(1,28)=17.04, p<.0005 ; F 2(1,29)=10.46, p<.005)$. Targets following accented words were responded to more slowly than targets following deaccented words, although this effect was significant in the subjects analysis only $(F 1(1,28)=5.31, p<.05 ; F 2(1,29)=3.62, p>.05)$. The priming effect for accented words $(43 \mathrm{~ms})$ was significant when analyzed separately $(F 1(1,28)=9.27, p<.005 ; F 2(1,29)=8.47$, $p<.01)$ but the priming effect for deaccented words $(24 \mathrm{~ms})$ was only significant by subjects $(F 1(1,28)=4.87, p<.05 ; F 2(1,29)=1.48, p>.2)$. There was, however, no significant interaction between relatedness and accent $(F 1(1,28)=1.04, p>.3 ; F 2(1,29)=1.44, p>.2)$.

In the error analysis the only significant results were an effect of relatedness for accented targets $(F 1(1,28)=5.30, p<.05 ; F 2(1,29)=2.07, p>.1)$ and an interaction between accent and relatedness $(F 1(1,28)=5.06, p<.05 ; F 2(1,29)=2.83, p>.1)$, both of which were significant only by subjects.

\subsubsection{Discussion}

In contrast to all the preceding experiments with materials consisting of complete sentences, Experiment $4 \mathrm{C}$ produced reliable associative priming. This suggests that sentence prosody can influence the way in which words' meanings are incorporated into the overall meaning of a sentence. When prime words appeared in prosodically neutral sentences,

Table 4

Associative priming results, Experiment $4 \mathrm{C}$ (inter stimulus interval $=0 \mathrm{~ms}$ )

\begin{tabular}{|c|c|c|c|c|}
\hline \multirow[t]{4}{*}{ Measure } & \multirow{2}{*}{\multicolumn{2}{|c|}{$\begin{array}{l}\text { Accented prime } \\
\text { Prime-target relationship }\end{array}$}} & \multirow{2}{*}{\multicolumn{2}{|c|}{$\begin{array}{l}\text { Deaccented prime } \\
\text { Prime-target relationship }\end{array}$}} \\
\hline & & & & \\
\hline & Related & Unrelated & Related & Unrelated \\
\hline & DATE-time & COME-time & date-time & come-time \\
\hline RT & 588 & 631 & 576 & 600 \\
\hline Error & 0.4 & 2.1 & 3.0 & 1.2 \\
\hline
\end{tabular}

Mean reaction times (RT, in milliseconds, from target onset) and mean percentage error rates for lexical decisions to visual target words in each priming condition. 
there was no detectable priming. When exactly the same targets were preceded by exactly the same primes, but where the primes were in sentences containing contrastive accents, priming was observed.

The results of Experiment $4 \mathrm{C}$ suggest further that contrastive accent acts not to increase semantic processing on the accented word alone, but rather to encourage fuller processing of the meaning of the sentence as a whole. If the accented primes alone had facilitated target responses, this would have suggested that words bearing accent are processed more deeply, such that semantic associates of those words are activated. But there was also facilitation when contrastive accents were applied later in the sentences than the critical prime words. Although this effect was not significant in the by-items analysis, the interaction of relatedness and accent was not significant. These findings suggest that there was indeed some activation of the associates of the deaccented primes. Deeper semantic processing of words other than the accented word in a sentence may be triggered by the contrastive function of the accent, such that listeners are encouraged not only to consider the meaning of the sentence, but also to construct the alternative scenario implicit in the utterance. In the deaccented date sentence ("He suggested that it was really the date of the ELECTION that mattered"), for example, listeners may have considered the possibility of dates of other events, and hence have activated associated words, such as the target time.

The results of Experiment $4 \mathrm{C}$ raise the possibility that the intonation or prosody of the materials in previous studies showing associative priming in sentence contexts could have encouraged more extensive processing of the primes, and hence could have induced the priming effects. We therefore contacted the authors of studies for which there is as yet no obvious explanation for the priming that was observed (i.e., those studies in which the primes were not at the ends of sentences or clauses, or at a truncation point, and in which, in addition, the associative relationship between prime and target was not relevant to the meaning of the sentence). Shillcock (personal communication) pointed out that the materials in Shillcock (1990) were spoken in a slow and careful manner. Swinney (personal communication) indicated that main stress may have been placed on the prime words in the Swinney (1979) sentences. We were sent the materials from the Tabossi et al. (1995) study, however, and these sentences were spoken with a fairly neutral intonation. A question remains though as to how much weight to assign to the confict between these results. There may be many unpublished studies which, like Experiment 1B, failed to detect associative priming in semantically and prosodically neutral sentence contexts. That is, it may well be that the normal pattern under these conditions is that of no associative priming.

Because the sentences in Experiment 4C were necessarily different from those used in the other sentence experiments, there is a possibility that the primes in $4 \mathrm{C}$ might somehow have been more predictable or plausible than those in the previous sentences. To investigate this possibility we conducted a further experiment to compare the original sentence materials from Experiment $1 \mathrm{~B}$ with those from $4 \mathrm{C}$ in both a cloze procedure and in a plausibility rating task.

\subsection{Experiment 4D: Control data}

\subsubsection{Method}

Both the cloze and rating tasks were based on the sentences with monosyllabic primes used initially in Experiment 1B (Appendix B) and those used in Experiment 4C (Appendix D). Twelve participants saw the sentences from Experiment 1B, and 12 saw 
the sentences from Experiment 4C. All participants performed the cloze task before the rating task.

In the cloze task participants were shown written versions of the sentences up to, but excluding, the prime word. The instructions were as follows: "Below is a list of the beginnings of some sentences. Your task is simply to read carefully the beginning of each sentence and then continue the sentence by writing down a word or phrase. Please read carefully and put down the first words that spring to mind as continuations."

The cloze task was immediately followed by the rating task. Here participants were asked to rate the plausibility of the target, given the prime-bearing sentence, up to and including the prime. Written sentence preambles ended with the prime word followed by "..." and the related target word, offset to the right and printed in upper case. Beneath each item, a 5 point rating scale was printed with labels, "unrelated," "slightly related," "related," "very related," and "extremely related."

5.4.1.1. Participants. Twenty-four members of the MRC Cognition and Brain Sciences volunteer panel took part. They were similar in age range and education to previous participants.

\subsubsection{Results and discussion}

As in Experiment 4C, results involving the prime-target pairs rock-hard and vat-tax were excluded from the analyses. In the cloze task participants hardly ever produced the prime word as a completion. The correct completion was produced $0.52 \%$ of the time for the Experiment $1 \mathrm{~B}$ materials and $2.34 \%$ of the time for Experiment $4 \mathrm{C}$ materials. The mean rating scores for the materials for Experiments $2 \mathrm{~A}$ and $4 \mathrm{C}$ were 2.77 and 3.19 respectively. This difference was only significant by items $(F 1(1,22)=3.45, p>.05 ; F 2(1,29)=15.93$, $p<.001)$.

The results from the cloze task show that the primes were very unpredictable in their contexts, and, statistically, equally so across the two sets of sentences. But although the difference in rated plausibility was very small, it was significant in the items analysis. Correlational tests were therefore carried out, comparing the size of the RT priming effects in the experiments with the rating scores. None of these correlations was significant. It is therefore very unlikely that the small increase in rated plausibility of the Experiment 4C materials relative to the earlier sentence materials is responsible for the emergence of priming in Experiment $4 \mathrm{C}$. The comparison of Experiments $3 \mathrm{~B}$ and $3 \mathrm{C}$ also shows that target plausibility is unlikely to be the sole cause of priming effects: the truncated sentence materials produced significant priming in Experiment 3C, while the full sentences in Experiment 3B did not, even though target plausibility was the same in both experiments. It seems reasonable to conclude that the emergence of priming in Experiment $4 \mathrm{C}$ was instead due, at least primarily, to the prosodic manipulation that was introduced.

In six experiments using cross-modal associative priming in complete sentences (Experiments $1 \mathrm{~B}, 3 \mathrm{~A}, 3 \mathrm{~B}, 4 \mathrm{~A}, 4 \mathrm{~B}$, and $4 \mathrm{C}$ ), Experiment $4 \mathrm{C}$ was the only case where related targets were responded to significantly more quickly than unrelated targets. This is despite the fact that the same words produce significant associative priming when they were presented in isolation (Experiment 1A), or at the end of a truncated sentence (Experiment 3C). As we suggested earlier, this may be because the effective contexts for priming (Williams, 1988) provided by isolated words and by sentences may be different. Words in isolation are the 
only available context, so their meanings should be incorporated into the effective context of the target, and associative priming should result.

The effective context of a sentence, however, is likely to be the interpretation of the sentence. We argued earlier that the construction of a sentence-level interpretation could inhibit word-level representations, or produce a different kind of representation from a word-level representation, blocking associative priming. The results of Experiments 3C and $4 \mathrm{C}$, in combination with those of Experiments $1 \mathrm{~B}, 3 \mathrm{~A}, 3 \mathrm{~B}, 4 \mathrm{~A}$, and $4 \mathrm{~B}$, suggest that the richness of the interpretation of a sentence (and hence whether or not associative priming will be found) can vary, such that sentences can nevertheless sometimes be effective contexts for associative priming. One way to manipulate depth of processing of primes in sentences would of course be to structure the pre-prime portions of the sentences such as to bias interpretation toward a meaning of the prime that is associated with the target (Tabossi, 1988a). Experiment 3C shows that manipulation of prime prominence by truncation of the speech signal can have a similar effect. Experiment $4 \mathrm{C}$ shows that this can also be achieved by manipulation of sentence prosody.

The pattern of results across our experiments is more similar to that reported by Williams (1988) and Tabossi (1988a) than to that reported by Shillcock (1990), and by others who have found significant priming effects in sentences. In part this may be explained by the fact that, to our knowledge, only our study and the Williams study examined priming in both sentences and isolated words. Any researcher failing to find cross-modal priming in sentences in a single experiment might be inclined to conclude that there was a problem with their materials, or that the experiment lacked power. The fact that both we and Williams observed priming from isolated words shows that any failure to observe priming in sentences in these studies is not due to problems with the specific primes and targets used.

Furthermore, in our study, the fact that we failed to obtain priming in five out of seven experiments means that any single null result cannot readily be dismissed as a type II error. Averaging over all of the sentence conditions with non-embedded primes and complete sentences, other than Experiment 4C which used the accent manipulation, the mean crossmodal associative priming effect is $3 \mathrm{~ms}$. This pools data over 192 subjects. Although the exact interpretation of this null result needs to take account of the fact that there do appear to be conditions under which cross-modal semantic priming effects can be obtained in sentences, the simple conclusion must be that words in sentences do not automatically produce associative priming. Even when listeners hear non-embedded monosyllabic words, where there can be no doubt that those words are accessed, this does not necessarily result in reliable cross-modal associative priming. As we discussed in the introduction, however, the absence of priming does not necessarily imply that there has been no lexical activation. Cross-modal associative priming should therefore not be used to determine whether or not embedded words are accessed in continuous speech.

\section{General discussion}

The priming of phonological representations of lexical forms patterns differently from the priming of conceptual representations. A simple model in which the phonological and conceptual representations of each word exist as separate but tightly linked parts of the same lexical entry is thus not tenable.

In our 10 cross-modal priming experiments we have compared form-based (identity) priming with associative priming, isolated word primes with sentential primes, and primes 
which were words intended by the speakers (non-embedded words, such as date) with primes which were unintended words, spuriously embedded in longer words (such as date in sedate). We also examined the timing of lexical activation by manipulating the primetarget interval, and we encouraged variation in depth of processing by manipulating the semantic complexity and prosodic structure of sentences. Together these comparisons provide a comprehensive picture of the availability of lexical representations at different levels of processing during speech comprehension.

\subsection{Phonological activation}

The identity priming task is assumed to tap the activation of mental representations of the phonological form of words. Consistent with this assumption, we observed differences between the identity priming effects in Experiments $2 \mathrm{~A}$ and $2 \mathrm{~B}$ and the associative priming effects with exactly the same materials in Experiments 1A and 1B. Fig. 2 displays the mean priming effects across these four experiments. Effects were not the same in the two types of priming task. For example, there was reliable identity priming from non-embedded words in sentences (Experiment 2B), but no associative priming from these materials (Experiment 1B). Such differences suggest that identity priming does not reflect conceptual activation.

Given this assumption about the source of identity priming, interpretation of these results (Fig. 2a) is quite straightforward. Identity priming from monosyllabic, non-embedded words was facilitatory and robust, whether the words appeared in isolation (Experiment 2A), or in sentences (Experiment 2B). This suggests that the phonological representations of the lexical tokens of words such as date were activated whether listeners heard only that word, or a sentence containing the word. As shown in Fig. 2a, however, the pattern for embedded words (bisyllabic primes such as sedate) is quite different. Responses to date, for example, tended to be slower after the prime sedate than after an unrelated prime. For isolated primes (Experiment 2A), this inhibitory effect was small and non-significant. But in sentences (Experiment 2B) it was robust, and of similar magnitude

a

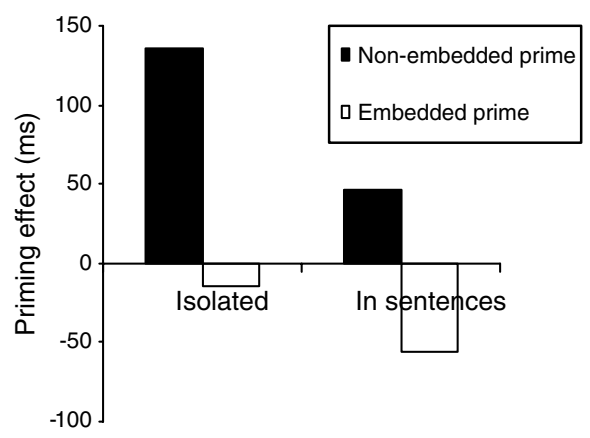

Prime type b Associative priming

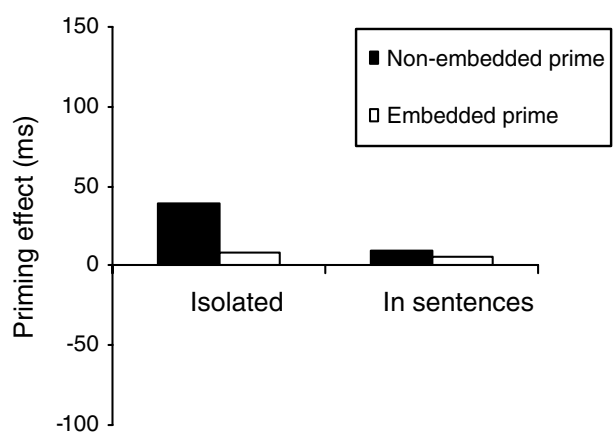

Prime type

Fig. 2. Identity priming (a) and associative priming (b) from non-embedded and embedded words, in isolation and in prosodically neutral sentences (Experiments 1 and 2). Priming effects are mean reaction time differences, in milliseconds (ms), between responses to targets after unrelated primes and responses to targets after related primes (positive numbers reflect facilitation relative to the unrelated condition; negative numbers reflect inhibition). The values for associative priming are those collapsing over Inter Stimulus Interval. 
to the facilitatory effect for non-embedded words. This pattern of results suggests that identity priming is being driven here by a representation that is first activated and then strongly suppressed during the recognition process. As we argued above, there must be some sense in which a representation of the embedded word is initially activated, or else it would not be inhibited any more than a completely unrelated word. In both Shortlist (Norris, 1994) and TRACE (McClelland \& Elman, 1986), phonological representations of embedded words are activated by perceptual input and then inhibited through lexical competition (primarily from the carrier word), as indicated by the simulations in Fig. 1. The pattern of identity priming for embedded words is exactly what would be expected if the priming effect were being driven by the activation of these token representations.

It is worth emphasising that the different effects of identity priming for embedded and non-embedded words constitute further support for our assumption that identity priming reflects overlap between prime and target word at the level of lexical form. The phonological overlap between the target word and the prelexical representation of the input is identical in both cases. Any prelexical phonological priming should therefore have been equivalent for both embedded and non-embedded words.

The identity priming results thus suggest that although the phonological representations of both non-embedded and embedded words are activated during speech processing, the temporal dynamics of their activation profiles differ. The phonological representations of words that a speaker intends are activated, and remain so at least until the acoustic offset of those words. The phonological representations of words that a speaker does not intend (embedded words) are also activated, but are rapidly inhibited through lexical competition with the words which are part of the speaker's message. We suggested in the introduction that we might need to manipulate ISI to examine the time-course of activation of phonological representations. The results of Experiments $2 \mathrm{~A}$ and $2 \mathrm{~B}$ make it clear that this manipulation is unnecessary. It appears that by the offset of a carrier word such as sedate, date has already lost the competition.

In addition to competition between phonological representations, there may be another reason why the representations of embedded words do not remain activated for long. This is that there may be acoustic-phonetic information in the speech signal which helps listeners to distinguish between the words speakers intend and words which are spuriously activated. Gow and Gordon (1995), for example, argued that their failure to observe activation of words such as lips in tulips was because of subtle durational differences between word-initial consonants and non-initial consonants (specifically, the [1] of lips tends to be longer than the [1] of tulips). But this failure may have been due to the use of associative cross-modal priming, which, as we have shown here, does not appear to provide a reliable measure of lexical activation (see below for further discussion). More recent studies using other techniques (cross-modal identity priming: Davis et al., 2002; tracking of eye movements: Salverda, Dahan, \& McQueen, 2003), however, have also suggested that there are subtle acoustic differences between word-initial embedded words and non-embedded words (such as cap in captain and cap in cap tucked), and that these differences modulate lexical activation. Such findings suggest that the acoustic differences between word-final embedded words and non-embedded words observed by Gow and Gordon may indeed affect lexical activation. There may thus be two inhibitory forces, bottom-up mismatch and lexical competition, which deactivate words embedded in other words. Nevertheless, the inhibitory priming observed in Experiments 2A and 2B suggests that phonological word forms such as date are activated, albeit briefly, when listeners hear carrier words such as sedate. 


\subsection{Conceptual activation}

Our findings for the monosyllabic (non-embedded) primes indicate that associative priming does not follow automatically when listeners hear spoken words. As shown in Fig. 2b, primes such as date do appear to facilitate responses to their associates (e.g., time) when the primes appear in isolation (Experiment 1A), but not necessarily when they appear in sentence contexts (Experiment 1B). There was no associative priming from words embedded in carrier words whether the carrier words appeared in isolation or in sentence contexts. Our data, especially when taken in conjunction with those of Williams (1988), therefore make at least one thing very clear: Associative priming cannot be used as a direct and automatic measure of lexical access.

Fig. 3 summarizes the associative priming results for non-embedded words in sentence contexts. In five different experiments in which listeners heard complete sentences we manipulated the speaker, the proportion of related trials, the nature of the secondary task, and the semantic complexity of the sentences, and found no associative priming. As we pointed out in the discussion of Experiment 4, acceptance of this null effect is therefore unlikely to be a type II error. The only conditions under which we were able to detect associative priming in sentences were when we manipulated the prosody of the sentences (the placement of contrastive accent; Experiment 4C) and when the sentences were truncated immediately after the prime (Experiment 3C). These results suggest that cross-modal associative priming does not tap automatically into any of the lexical representations involved in word recognition.

Another conclusion can be drawn from a comparison of the identity and associative priming results (see Fig. 2). Although form-based priming (date-date) was found from monosyllabic, non-embedded words in sentences (Experiment 2B), exactly the same primes failed to produce associative priming (date-time; Experiment 1B). Likewise, these two experiments also show that the same bisyllabic words which produced form-based inhibition (sedate-date) produced no associative priming (sedate-time). If, as we argued above, facilitatory and inhibitory identity priming reflect activation of phonological lexical representations, then these dissociations which we have established indicate that associative priming does not reflect activation of phonological lexical representations.

What then does cross-modal associative priming reflect? We suggest that it measures conceptual activation associated with the current interpretation of an utterance. Note that

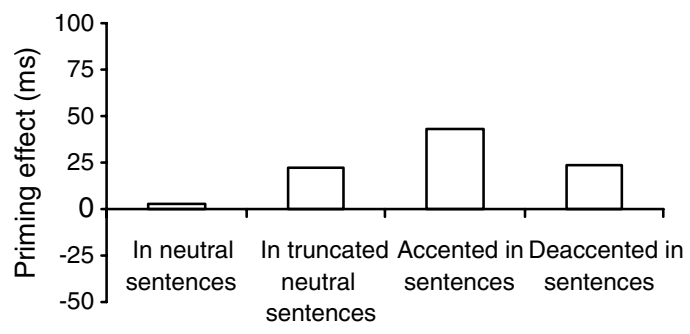

Prime type

Fig. 3. Associative priming from non-embedded words in sentences. Priming effects are given for words in prosodically neutral sentences (collapsing over Experiments 1B, 3A, 3B, 4A, and 4B), for words at the end of truncated versions of those sentences (Experiment $3 \mathrm{C}$ ), and for accented and deaccented words in sentences with contrastive accent (Experiment 4C). Priming effects are mean reaction time differences, in milliseconds (ms), between responses to targets after unrelated primes and responses to targets after related primes (positive numbers reflect facilitation relative to the unrelated condition). 
the conceptual representation of an utterance must be dynamically constructed as it can quite possibly be unique. Furthermore, the same set of words in a different order will have a quite different meaning. It therefore seems unlikely that priming at this level could be explained entirely in terms of spreading activation in a network of lexical representations.

According to this view, the contribution of individual words to associative priming will be determined by the extent to which those words are being incorporated into the interpretation of the sentence. When listeners hear complete sentences, it is reasonable to assume that they construct interpretations of the meanings of those sentences. But such interpretations may be relatively shallow under the conditions used in Experiments 1B, 3A, 3B, 4A, and $4 \mathrm{~B}$, that is, where the sentences were not in any discourse context, where a concurrent lexical decision task had to be performed, and where the secondary task (recognition or repetition) focused more on the form than on the meaning of the sentences. To use the terminology of Foss and Ross (1983), the effective context of the targets under these conditions may not have involved much of the specific lexical semantics of the prime words.

This account suggests that it should be possible to observe associative priming from primes in sentence contexts if listeners are encouraged to integrate prime meanings more fully into the overall interpretation of the sentence. While manipulation of sentential complexity (Experiment 4B) failed to induce reliable facilitation of target responses, manipulation of sentence prosody (Experiment 4C) did produce priming. Responses to targets were faster after associated primes than after unrelated primes, both when primes were accented and when they were deaccented. That is, accent did not simply have a local effect on the accented word itself. It appears that varying contrastive accent induced greater depth of processing of the sentences. For an accented word, this may involve stronger activation of the word's semantics not only because the intonation contour draws the listener's attention to that word but also because contrastive accent serves the function of setting up a semantic contrast between the scenario described in the sentence (e.g., the DATE of the election) and some alternative scenario (e.g., the election outcome). The contrastive function of the prosodic contour may also explain why priming was observed from deaccented words. Here, the semantics of the prime are still involved in the contrast (e.g., the date of the ELECTION, rather than the date of some other event).

Sentence prosody and sentential complexity are not the only factors which can modulate the importance of a prime in a sentence context. As discussed earlier, the position of the prime in the sentence and the availability of a discourse context may determine the extent to which the listener attends to a prime. More radical manipulations have included truncation of the prime-bearing sentence after the prime and presenting the prime in isolation rather than in a sentence. Thus, when we terminated the sentence materials at the acoustic offset of the primes (Experiment 3C), we drew the listener's attention to the primes and thus encouraged retrieval of the semantics of those primes. This is likely to involve the activation of associated words, and thus an associative priming effect. As in the Williams (1988) study, we also observed associative priming when prime words were presented in isolation. Here, in the absence of a larger context, the prime is the effective context for target responses. When the utterance consists only of an isolated word, its interpretation is likely to involve the full semantic representation of that word. This is likely in turn to involve activation of semantically associated words, and hence associative priming.

This account also explains why cross-modal priming for associates of contextually inappropriate meanings of homophones has sometimes been observed. We suggest that one or more of the above factors encouraged prime processing in the studies showing such effects 
(e.g., prosody and, in Experiment 1, discourse context in Swinney, 1979; complex lead-in sentences in Cutler, 1986; clause-final primes in Tabossi, 1988b). When attention is directed to a prime in one of these ways, priming can arise even for contextually inappropriate meanings. In Blutner and Sommer (1988), for example, no priming was observed at $0 \mathrm{~ms}$ ISI for either meaning of ambiguous primes when a previously presented question focussed listeners' attention away from the primes, but there was priming of responses to associates of both the appropriate and the inappropriate meanings of the primes when the primes were in focus. When a given word is brought more fully to the listener's attention as being relevant for ongoing utterance interpretation, the lexical semantics of that word can be activated more strongly, and associative priming may thus be found even for a meaning of that word that ultimately does not fit into that interpretation.

Cross-modal associative priming can no longer be taken as providing a direct measure of the activation of word meaning representations. If it were, words that produce priming when presented in lists should also produce priming when presented as part of a sentence. Both our own data and the older data from Williams (1988) show that this is not the case. As we have already argued, one reason for this is that the task appears to reflect the interpretation of the utterance, rather than of individual words (unless there is only one word in the utterance, or listeners are encouraged to process the meaning of the primes more deeply). Another reason is that it is difficult to interpret the failure to observe priming, as Marí-Beffa et al. (2000) pointed out. It remains a possibility that even when there is no priming, the lexical semantic representations that would be needed for spreading associations are activated, but that these are quickly suppressed because the task is to understand a sentence rather than to attend to an individual word. On this view, there is always activation of lexical semantics, but it is suppressed unless it is relevant to the construction of an utterance interpretation. In any case, it is clear that, given the dissociation between wordform activation and conceptual activation, a simple account of cross-modal associative priming based on automatic spread of activation is not tenable. Lexical access does not automatically lead to robust activation of a word's semantic associates.

\subsection{Modeling speech comprehension}

The results of this study suggest that spoken language comprehension involves processing at a number of distinct levels of representation. We have argued, on the basis of the identity priming data, that processing of phonological word-form information involves the use of token representations of candidate words, and that the activation of these representations reflects the strength of support that those words have as perceptual hypotheses at any moment in time. We have also argued that associative priming reflects the activation of the developing conceptual representation of the current utterance, and not access to lexical representations themselves. We thus propose that the representations at both the form and meaning levels which are used in speech comprehension are not only distinct from each other, but also from the representations stored in long-term lexical memory of the phonological form and the meaning of words.

Token phonological representations stand as hypotheses about the presence of particular word forms at specific points in a given utterance. They therefore allow the listener to recognize multiple occurrences of the same word in an utterance. Furthermore, token phonological representations provide an efficient means for continuous speech recognition. Continuous speech is a highly ambiguous code: at any one moment in the unfolding of an utterance, the 
signal may be more or less consistent with many different lexical hypotheses, which may begin and end at many possible locations. An efficient way to recognize the words that a speaker actually intended is therefore to consider all of the plausible lexical hypotheses in parallel, and to have some form of competition between those hypotheses. As Norris (1994) has argued, however, such an approach becomes implausible if too many words (i.e., potentially the entire lexicon) have to be considered in parallel. In the Shortlist model, therefore, there is a distinction between the long-term store of lexical knowledge and the token words that are considered at any moment in time. Word recognition in Shortlist consists of a search of the lexical store, followed by the construction of a shortlist of word tokens which contains only the most plausible lexical hypotheses for the current stretch of speech. Phonological tokens thus provide a framework in which the parsing problem of continuous speech can be solved.

These arguments, and our present results, support models of speech processing which distinguish between stored phonological knowledge about words and token representations, such as the Shortlist model. The results challenge models which do not make this distinction such as PARSYN (Luce, Goldinger, Auer, \& Vitevitch, 2000) and the Distributed Cohort Model (DCM; Gaskell \& Marslen-Wilson, 1997). Note that although there is no explicit distinction between a long-term lexical store and token phonological representations in TRACE, McClelland and Elman (1986) do suggest that such a distinction would be necessary in a more fully-specified version of the model.

Our data on identity priming present an acute problem for the DCM. In this model, each word is represented as a vector of activation values over a set of units; some of these units represent phonological information, others represent semantic information. There is a single bank of nodes representing the phonology of the input. In Gaskell and MarslenWilson (1997), this is a representation of the onset, nucleus and coda of the current input syllable. Identity priming is driven by this representation (Gaskell \& Marslen-Wilson, 2002), and listeners can also use this representation to perform tasks such as phonetic classification. The phonological representation of a word like trombone should thus have the representation of bone as a constituent. More specifically, the representations of the word bone and of the second syllable of trombone must be identical. It should thus be impossible to activate the phonological representation of a word without also activating the representation of embedded words. In the DCM, therefore, if a carrier word like trombone is activated, it is not possible to simultaneously inhibit the phonological representation of the embedded word bone, contrary to what we observed in Experiment 2B.

The solution to this problem is to postulate token representations of candidate words which (unlike the phonological word-form representations in the DCM and PARSYN) are distinct from the representations of phonological form that are held in long-term memory. The token representations of embedded words and their carriers are different, and can compete with each other when activated by the carrier word in the input. Note that on such a view, activation of the phonological representations of multiple words is mandatory, that is, multiple word forms must be considered in parallel. This contrasts with the case of word meanings. Multiple interpretations of an utterance do not have to be maintained in parallel. Although listeners may need to access the entire contents of a lexical representation to select the contextually appropriate semantic information, the developing conceptual interpretation of the utterance should only incorporate contextually relevant meaning. For example, we have suggested that many factors may influence how deeply listeners analyze the words in the sentences they hear. Meaning activation thus appears to be much more dependent on the current demands of the listening situation than phonological activation. 
Nevertheless, as with the phonological level, we suggest that there is also a distinction to be made between on-line and stored conceptual representations. We argue that the current interpretation of an utterance contains representations which are distinct from stored lexical-semantic representations. The interpretation of a sentence can therefore be considered to contain token representations of word meanings. At the most trivial level, listeners can represent the meaning of a sentence that contains more than one occurrence of the same word. The meaning of a sentence is thus much more than just the activated meanings of its constituent words.

The dissociation we observed - isolated words produce associative priming but the same words in sentences do not-is consistent with there being a distinction between stored semantic representations and a temporary representation of the current utterance's interpretation. If associative priming were the consequence of the activation of a word's semantic representation in the lexicon, priming would not be expected to change as a function of whether or not the word appears in a sentence context. In short, the effective context account of associative priming that we (and Williams, 1988) have offered makes the assumption that utterance interpretation is based not on the transient activation of stored lexical-semantic representations (i.e., of word types), but instead on a separate and temporary token-based representation of the current utterance.

The second dissociation we observed was between identity and associative priming. Whereas identity priming reflected activation of token representations of lexical phonological form, associative priming appeared to be driven only by sentence-level representations. A dissociation between identity and associative priming has also been reported by Gaskell and Marslen-Wilson (2002). They found that associative priming (and, in separate experiments, semantic priming between word pairs, such as synonyms, that were not strongly associated) was more affected by competition between words than identity priming. There was robust identity priming from words with few lexical competitors (i.e., words with early uniqueness points) and from words with more competitors (words with late uniqueness points), even when only fragments of the words served as primes. In contrast, however, there was more meaning-based priming (at least for longer fragments and complete word primes) for the early unique words than for the late unique words. Gaskell and MarslenWilson (2002) interpreted their data in terms of the DCM. They pointed out that when there are a number of competitor words consistent with a given fragment of speech, these competitors all have at least some phonological overlap, but may have no semantic overlap. The phonological components of the lexical network in the DCM can thus settle into a more stable state more rapidly than the semantic components.

It might therefore be possible to provide a similar account within the DCM for the dissociation we observed between identity and associative priming (the semantic component needing more time to settle than the phonological component). But, as we have already argued, the DCM appears unable to explain the inhibition we observed from embedded words in identity priming. Furthermore, because cross-modal associative priming in the DCM is a function of the activation of the semantic component of the network (i.e., the stored semantic knowledge about words, rather than token meaning representations), the model is challenged by the variability we observed in associative priming (between word and sentence primes, and among different types of sentences).

We therefore propose that the mental lexicon contains separable phonological and semantic representations for each word, and that this knowledge is used to construct token representations at both the phonological and the meaning level during speech comprehension. We have argued that the activation of token phonological representations is an auto- 
matic component of the speech recognition process which leads to form-based priming. In contrast, lexical activation does not automatically produce semantic priming. Semantic priming is a consequence of the activation of representations of utterance meaning. The construction or activation of utterance meaning is not an automatic consequence of lexical activation; it appears to depend on the demands of the listening situation, that is, on the kind of interpretation that the listener is attempting to build. This account can explain the dissociations and variations in priming, as a function of the type of prime and the type of target, that were observed in the present series of experiments.

\section{Conclusions}

In trying to understand the way in which lexical representations are activated during speech comprehension one must consider multiple levels of processing and representation. In principle, form-based priming could be driven by at least four different types of phonological representation: prelexical representations, lexical representations themselves, token-based representations, or the final post-competition representation of a word. A similar distinction is possible at the conceptual level. Priming could be driven by initial access to lexical representations, by the processes involved in selecting the contextually appropriate meaning from the lexical representations, or from the semantic information actually incorporated into the interpretation of the utterance. Since there can be different processes operating at each of these levels, it is necessary to examine them by attempting to tap selectively into different aspects of processing. We achieved that in the present study by comparing identity priming with associative priming, by comparing primes in isolation with primes in sentences, and by varying whether primes were words intended by speakers or were spuriously part of the speech materials (embedded words).

The data reported here indicate that form-based priming reflects the activation of the token candidates involved in the lexical competition process postulated by models such as TRACE and Shortlist. Cross-modal identity priming tracks the activation and inhibition of these token representations. In contrast, associative priming appears to be driven by the developing conceptual interpretation of the utterance. Cross-modal associative priming does not follow automatically from the lexical access process itself. However, the contribution that individual words make to the utterance interpretation can be modulated. Listeners can be encouraged to incorporate the semantics of particular words into their interpretations of utterances by manipulations which draw their attention to those words: presentation in isolation, for example, or truncation of an ongoing sentence, or manipulation of contrastive accents in the sentences' prosody. These manipulations could give the impression that priming is being driven by the lexical representation itself. But identity and associative priming are driven by quite different representations that are not tightly coupled. The phonological form of a word can produce priming even if there is no sign of priming from the word's conceptual representation.

Finally, one might ask why priming is produced by these particular representations and processes (token phonological form, and utterance interpretation) and not by any others (such as lexical access itself). One tentative answer is that while many other representations must be accessed, these dynamically constructed representations are the focus of most of the active computation required for speech comprehension. The competition process is the final and most important part of form-based processing. Once the competition process is complete the word has been identified and its form need no longer be considered. Similarly, the development of the utterance interpretation is the final and most important phase in conceptual processing. 


\section{Acknowledgments}

Some of this work was reported at the 13th Annual CUNY Conference on Human Sentence Processing, La Jolla, California, in March 2000. We thank Francis Nolan, Jonathan Rogers, Jane Hall, and Evelien Akker for assistance, and Ardi Roelofs, Richard Shillcock, and Louisa Slowiaczek for comments on an earlier version of the manuscript.

\section{Appendix A. Experimental materials}

\begin{tabular}{|c|c|c|c|c|}
\hline & $\begin{array}{l}\text { Non-embedded } \\
\text { prime }\end{array}$ & $\begin{array}{l}\text { Embedded } \\
\text { prime }\end{array}$ & $\begin{array}{l}\text { Related } \\
\text { target }\end{array}$ & $\begin{array}{l}\text { Unrelated } \\
\text { target }\end{array}$ \\
\hline 1. & date & sedate & time & go \\
\hline 2. & come & succumb & go & time \\
\hline 3. & stream & extreme & river & chair \\
\hline 4. & seat & receipt & chair & river \\
\hline 5. & tick & frantic & cross & saucer \\
\hline 6. & cup & hiccup & saucer & cross \\
\hline 7. & test & protest & exam & grape \\
\hline 8. & vine & divine & grape & exam \\
\hline 9. & give & forgive & take & day \\
\hline 10. & night & ignite & day & take \\
\hline 11. & rock & baroque & hard & $\operatorname{tax}$ \\
\hline 12. & vat & cravat & $\operatorname{tax}$ & hard \\
\hline 13. & bone & trombone & $\operatorname{dog}$ & coffee \\
\hline 14. & tea & settee & coffee & dog \\
\hline 15. & gun & begun & shoot & trousers \\
\hline 16. & crease & decrease & trousers & shoot \\
\hline 17. & wrong & sarong & right & far \\
\hline 18. & near & veneer & far & right \\
\hline 19. & nine & benign & ten & short \\
\hline 20. & port & report & wine & rent \\
\hline 21. & lease & police & rent & wine \\
\hline 22. & rain & terrain & shine & apple \\
\hline 23. & pear & prepare & apple & shine \\
\hline 24. & soon & bassoon & later & high \\
\hline 25. & low & hello & high & later \\
\hline 26. & late & relate & early & car \\
\hline 27. & van & divan & car & early \\
\hline 28. & leaf & belief & tree & receive \\
\hline 29. & send & descend & receive & tree \\
\hline 30. & lips & ellipse & kiss & poem \\
\hline 31. & verse & reverse & poem & kiss \\
\hline 32. & long & prolong & short & ten \\
\hline
\end{tabular}

Note. In Experiments 3B, 3C, and 4C, only the non-embedded primes were presented. In Experiment 2, the targets, both related (identity) and unrelated, were the non-embedded primes. In item 12, vat is a common expression in British English used for Value Added Tax. 


\section{Appendix B. Sentences used in Experiments 1B, 2B, 3, and 4A}

1. They planned a date and place to meet with the ambassador. They planned sedate and placid meals with the ambassador.

2. The rebels were expected to be reasonable and to come and surrender to the government forces. The rebels were expected to be reasonable and succumb and surrender to the government forces.

3. Scientists agreed that the stream temperature changes had reduced the number of fish. Scientists agreed that extreme temperature changes had reduced the number of fish.

4. He gave up the seat for me out of some form of courtesy. He gave the receipt to me out of some form of courtesy.

5. The director made a tick mark at the end of each line. The director made frantic marks at the end of each line.

6. It was clear that the cup had attracted the attention of the antique dealer. It was clear the hiccup had attracted the attention of the antique dealer.

7. The inventors agreed to the test about their right to a patent. The inventors agreed to protest about their right to a patent.

8. They spotted a vine symbol in the mosaic. They spotted divine symbols in the mosaic.

9. We wondered whether we should give them such poor scores. We wondered whether to forgive them such poor scores.

10. She asked herself what would a night in the jungle be like. She asked herself what would ignite in the jungle for light.

11. They had not seen that there was a rock sculpture in the first room of the gallery. They had not seen that there was baroque sculpture in the first room of the gallery.

12. He didn't like the larger vat because it was more expensive than he could afford. He didn't like the large cravat because it was more expensive than he could afford.

13. He placed the old bone on the table very carefully. He placed the trombone on the table very carefully.

14. She remembered that the tea had been rather pleasant. She remembered the settee had been rather pleasant.

15. The decorator had a gun to apply the glue. The decorator had begun to apply the glue.

16. The effect of the treatment was to shrink and then crease the fabric quite a lot. The effect of the treatment was to shrink and decrease the fabric quite a lot.

17. They were surprised to find that the wrong costumes had been delivered for the party. They were surprised to find that sarong costumes had been delivered for the party.

18. It had to be a near match in colour to the original one. It had to be veneer matched in colour to the original one.

19. The new managing director had made nine recommendations for reorganising the company. The new managing director made benign recommendations for reorganising the company.

20. I passed on the port to the person sitting next to me. I passed the report to the person sitting next to me.

21. Everyone complained about the lease on the premises. Everyone complained about police on the premises.

22. On the last day of our journey there the rain took us completely by surprise. On the last day of our journey the terrain took us completely by surprise. 
23. The chef began with a pear and looked around for a knife. The chef began to prepare and looked around for a knife.

24. If it weren't for enthusiasts then soon music of the 17 th century could be forgotten. If it weren't for enthusiasts bassoon music of the 17 th century could be forgotten.

25. When I hear a low shout from across the street, I know the neighbours are home. When I hear hello shouted across the street, I know the neighbours are home.

26. The children will be late for the preview of the play. The children will relate their own version of the play.

27. We noticed the dirtier van outside the charity shop. We noticed the dirty divan outside the charity shop.

28. The lecturer tried to explain how a leaf develops in stages. The lecturer tried to explain how belief develops in stages.

29. They decided they would send a few flowers to the bereaved. They decided to descend a few floors more to the basement.

30. The colour of all the lips in the painting made it stand out from the others. The colour of the ellipse in the painting made it stand out from the others.

31. She told of her adventures in verse to an astonished audience. She told her adventures in reverse to an astonished audience.

32. Some meetings are long and complicate the discussion of issues. Some meetings prolong and complicate the discussion of issues.

Note. The critical prime words are given in italics. In Experiments $3 \mathrm{~B}$ and $3 \mathrm{C}$, only the first sentence of each pair was used.

\section{Appendix C. Sentences used in Experiment 4B}

1. The cultural delegation planned a date and place to meet with the ambassador. The cultural delegation planned sedate and placid meals with the ambassador.

2. The rebel soldiers were expected to be reasonable and to come and surrender to the government forces. The rebel soldiers were expected to be reasonable and succumb and surrender to the government forces.

3. The biologists at the conference agreed that the stream temperature changes had reduced the number of fish. The biologists at the conference agreed that extreme temperature changes had reduced the number of fish.

4. The businessman immediately gave up the seat for his partner. The businessman immediately gave the receipt to his partner.

5. The finance director made a tick mark at the end of each line in the ledger. The finance director made frantic marks at the end of each line in the ledger.

6. Everyone in the room noticed that the cup had attracted the attention of the antique dealer. Everyone in the room saw that the hiccup had attracted the attention of the antique dealer.

7. The angry inventors agreed to a test about their right to a patent. The angry inventors agreed to protest about their right to a patent.

8. The art historian spotted a vine symbol in the newly uncovered mosaic. The art historian spotted divine symbols in the newly uncovered mosaic.

9. The maths teachers wondered whether they should give their students poor scores. The maths teachers wondered whether to forgive their students' poor scores. 
10. The inexperienced author asked herself what would a night on the boat be like. The inexperienced author asked herself what would ignite on the boat to give light.

11. The visitor had not seen that there was a rock sculpture in the first room of the gallery. The visitor had not seen that there was baroque sculpture in the first room of the gallery.

12. Unfortunately the larger vat was more expensive than the customer could afford. Unfortunately the large cravat was more expensive than the customer could afford.

13. To avoid damage, the removals man wrapped the old bone carefully in tissue paper. To avoid damage, the removals man wrapped the trombone carefully in tissue paper.

14. The nurse was somewhat surprised to get any tea from her aunt. The nurse was somewhat surprised to get the settee from her aunt.

15. The painters saw that the decorator had a gun to apply glue to the wallpaper. The painters saw that the decorator had begun to apply glue to the wallpaper.

16. Heat treatment will shrink and then crease many fabrics quite a lot. Heat treatment will shrink and decrease many fabrics quite a lot.

17. The organisers were surprised to find that the wrong costumes had been delivered for the party. The organisers were surprised to find that sarong costumes had been delivered for the party.

18. The restorers wanted a near match in colour to the original shade. The restorers wanted veneer matched in colour to the original shade.

19. The new managing director had made nine recommendations for reorganising the company. The new managing director made benign recommendations for reorganising the company.

20. The headmaster passed on the port to the person sitting next to him. The headmaster passed the report to the person sitting next to him.

21. The bookshop owners complained about the lease on the premises. The bookshop owners complained about police on the premises.

22. On the last day of their journey there the rain took the disorganized travellers completely by surprise. On the last day of their journey the terrain took the disorganized travellers completely by surprise.

23. The TV chef began with a pear and looked around for a knife. The TV chef began to prepare and looked around for a knife.

24. If it weren't for enthusiasts then soon music of the 17 th century could be forgotten. If it weren't for enthusiasts bassoon music of the 17 th century could be forgotten.

25. When the family heard a low shout from across the street, they knew the neighbours were home. When the family heard hello shouted across the street, they knew the neighbours were home.

26. The second-year pupils would be late for the preview of the play, their teacher said. The second-year pupils would relate their own version of the play, their teacher said.

27. The observant policewoman noticed the dirtier van outside the charity shop. The observant policewoman noticed the dirty divan outside the charity shop.

28. The patient lecturer tried to explain how a leaf develops in stages. The patient lecturer tried to explain how belief develops in stages. 
29. The old couple decided they would send a few flowers to the bereaved. The old couple decided to descend a few floors more to the basement.

30. The bright colour of all the lips in the modern painting made it stand out from the more traditional works. The bright colour of the ellipse in the modern painting made it stand out from the more traditional works.

31. The explorer told of her adventures in verse to the astonished audience. The explorer told her adventures in reverse to the astonished audience.

32. Council meetings often are long and complicate the discussion of issues. Council meetings often prolong and complicate the discussion of issues.

Note. The critical prime words are given in italics.

\section{Appendix D. Sentences used in Experiment 4C}

1. He suggested that it was really the DATE of the ELECTION that mattered.

2. We hoped that the star would at least $C O M E$ to the FILM.

3. On the maps we could find no trace of the $S T R E A M$ we were LOOKING for.

4. I was surprised that the janitor offered his $S E A T$ to ME.

5. With great relief the secretary put a TICK against the LAST item on the list.

6. She was allowed no more than a CUP of the SOUP.

7. There were plans to replace the TEST of MANAGEMENT skills with an interview.

8. The workmen accidentally damaged the VINE in the COURTYARD.

9. The artist decided to GIVE the SCULPTURE to the charity.

10. He was confident that he could stand a NIGHT in the DESERT.

11. It made things harder that there was a $R O C K$ in the PATH.

12. They discussed the question of the $V A T$ on the OFFICE equipment.

13. I don't think you will find a BONE in THAT fish.

14. It is impossible to get $T E A$ in THAT cafe.

15. Nobody knew that he had a $G U N$ in EACH hand.

16. It was impossible to detect any $C R E A S E$ in the SPECIAL fabric.

17. It was established that the statement had been $W R O N G$ on TWO points.

18. The tourists wanted to be $N E A R$ to the LOUDSPEAKERS.

19. The best player had won NINE games without LOSS.

20. It was only when they were in PORT that they were REALLY safe.

21. The manager arranged to LEASE BOTH of the buildings.

22. Very luckily there was a great deal of RAIN in JULY.

23. Carefully the assistant positioned another PEAR on the ALREADY full platter.

24. Everyone was wondering how SOON the CRASH would occur.

25. It was important that the sign be $L O W$ enough for CHILDREN to read it.

26. They began to hope that nobody would be $L A T E$ for the OPENING.

27. The young couple decided that they would take the $V A N$ ONE more time.

28. For his project the boy described a $L E A F$ from the RARE plant.

29. He explained for the third time that he wanted to SEND a FAX.

30. The odd thing was the colour of the LIPS in the PAINTING.

31. We were required to learn a $V E R S E$ of the NEW anthem.

32. The set text was rather $L O N G$ for YOUNG readers. 
Note. The critical prime words are given in italics. In one version of each sentence the critical word was accented; in a second version a different word was accented. The two accented words are marked in capitals.

\section{References}

Akker, E., \& Cutler, A. (2003). Prosodic cues to semantic structure in native and nonnative listening. Bilingualism: Language and Cognition, 6, 81-96.

van Alphen, P. M., \& McQueen, J. M. (2006). The effect of Voice Onset Time differences on lexical access in Dutch. Journal of Experimental Psychology: Human Perception and Performance, 32, 178-196.

Andruski, J. E., Blumstein, S. E., \& Burton, M. (1994). The effect of subphonetic differences on lexical access. Cognition, 52, 163-187.

Blutner, R., \& Sommer, R. (1988). Sentence processing and lexical access: the influence of the focus-identifying task. Journal of Memory and Language, 27, 359-367.

Bölte, J., \& Coenen, E. (2002). Is phonological information mapped onto semantic information in a one-to-one manner? Brain and Language, 81, 384-397.

Boothroyd, A., \& Nittrouer, S. (1988). Mathematical treatment of context effects in phoneme and word recognition. Journal of the Acoustical Society of America, 84, 101-114.

Coenen, E., Zwitserlood, P., \& Bölte, J. (2001). Variation and assimilation in German: consequences for lexical access and representation. Language and Cognitive Processes, 16, 535-564.

Collins, A. M., \& Loftus, E. F. (1975). A spreading-activation theory of semantic processing. Psychological Review, 82, 407-428.

Colombo, L., \& Williams, J. (1990). Effects of word-level and sentence-level contexts upon word recognition. Memory \& Cognition, 18, 153-163.

Cooper, N., Cutler, A., \& Wales, R. (2002). Constraints of lexical stress on lexical access in English: evidence from native and nonnative listeners. Language and Speech, 45, 207-228.

Cutler, A. (1976). Phoneme monitoring reaction time as a function of preceding intonation contour. Perception \& Psychophysics, 20, 55-60.

Cutler, A. (1986). Forbear is a homophone: Lexical prosody does not constrain lexical access. Language and Speech, 29, 201-220.

Cutler, A. (in press). On prosodic salience and the processing of meaning. In R. Breheny \& H. Hendriks (Eds.), Language in context.

Cutler, A., Dahan, D., \& van Donselaar, W. (1997). Prosody in the comprehension of spoken language: a literature review. Language and Speech, 40, 141-201.

Cutler, A., \& van Donselaar, W. (2001). Voornaam is not a homophone: lexical prosody and lexical access in Dutch. Language and Speech, 44, 171-195.

Cutler, A., \& Fodor, J. A. (1979). Semantic focus and sentence comprehension. Cognition, 7, 49-59.

Cutler, A., McQueen, J. M., Norris, D., \& Somejuan, A. (2001). The roll of the silly ball. In E. Dupoux (Ed.), Language, brain and cognitive development: Essays in honor of Jacques Mehler (pp. 181-194). Cambridge, MA: MIT Press.

Cutler, A., \& Norris, D. (1988). The role of strong syllables in segmentation for lexical access. Journal of Experimental Psychology: Human Perception and Performance, 14, 113-121.

Dahan, D., Tanenhaus, M. K., \& Chambers, C. G. (2002). Accent and reference resolution in spoken-language comprehension. Journal of Memory and Language, 47, 292-314.

Dalrymple-Alford, E. C., \& Bundayr, B. (1966). Examination of some aspects of Stroop color-word test. Perceptual and Motor Skills, 23, 1211-1214.

Davis, M. H., Marslen-Wilson, W. D., \& Gaskell, M. G. (2002). Leading up the lexical garden path: Segmentation and ambiguity in spoken word recognition. Journal of Experimental Psychology: Human Perception and Performance, 28, 218-244.

Dell, G. S., Schwartz, M. F., Martin, N., Saffran, E. M., \& Gagnon, D. A. (1997). Lexical access in aphasic and nonaphasic speakers. Psychological Review, 104, 801-838.

van Donselaar, W., Koster, M., \& Cutler, A. (2005). Exploring the role of lexical stress in lexical recognition. Quarterly Journal of Experimental Psychology, 58 A, 251-273.

Forster, K. (1976). Accessing the mental lexicon. In R. J. Wales \& E. C. T. Walker (Eds.), New approaches to language mechanisms (pp. 257-288). Amsterdam: North-Holland. 
Foss, D. J., \& Ross, J. R. (1983). Great expectations: context effects during sentence processing. In G. Flores D’Arcais \& R. J. Jarvella (Eds.), The process of language understanding (pp. 169-191). Chichester: Wiley.

Friedrich, F. J., Henik, A., \& Tzelgov, J. (1991). Automatic processes in lexical access and spreading activation. Journal of Experimental Psychology: Human Perception and Performance, 17, 792-806.

Gaskell, M. G., \& Marslen-Wilson, W. (1996). Phonological variation and inference in lexical access. Journal of Experimental Psychology: Human Perception and Performance, 22, 144-158.

Gaskell, M. G., \& Marslen-Wilson, W. D. (1997). Integrating form and meaning: A distributed model of speech perception. Language and Cognitive Processes, 12, 613-656.

Gaskell, M. G., \& Marslen-Wilson, W. (2001). Lexical ambiguity resolution and spoken word recognition: bridging the gap. Journal of Memory and Language, 44, 325-349.

Gaskell, M. G., \& Marslen-Wilson, W. D. (2002). Representation and competition in the perception of spoken words. Cognitive Psychology, 45, 220-266.

Gaskell, G., Spinelli, E., \& Meunier, F. (2002). Perception of resyllabification in French. Memory \& Cognition, 30, 798-810.

Gow, D. W. (2002). Does English coronal place assimilation create lexical ambiguity? Journal of Experimental Psychology: Human Perception and Performance, 28, 163-179.

Gow, D. W., \& Gordon, P. C. (1995). Lexical and prelexical influences on word segmentation: evidence from priming. Journal of Experimental Psychology: Human Perception and Performance, 21, 344-359.

Hess, D. J., Foss, D. J., \& Carroll, P. (1995). Effects of global and local context on lexical processing during language comprehension. Journal of Experimental Psychology: General, 124, 62-82.

Hofland, K., \& Johansson, S. (1982). Word frequencies in British and American English. Harlow: Longman.

Huber, D. E., Shiffrin, R. M., Lyle, K. B., \& Ruys, K. I. (2001). Perception and preference in short-term word priming. Psychological Review, 108, 149-182.

Isel, F., \& Bacri, N. (1999). Spoken-word recognition: the access to embedded words. Brain and Language, 68 , $61-67$.

Janse, E. (2003). Production and perception of fast speech. Doctoral dissertation, University of Utrecht.

Kintsch, W. (1988). The role of knowledge in discourse comprehension: a construction integration model. Psychological Review, 95, 163-182.

Levelt, W. J. M., Roelofs, A., \& Meyer, A. S. (1999). A theory of lexical access in speech production. Behavioral and Brain Sciences, 22, 1-38.

Lucas, M. M. (1987). Frequency effects on the processing of ambiguous words in sentence contexts. Language and Speech, 30, 25-46.

Luce, P. A., \& Cluff, M. S. (1998). Delayed commitment in spoken word recognition: evidence from cross-modal priming. Perception \& Psychophysics, 60, 484-490.

Luce, P. A., Goldinger, S. D., Auer, E. T., \& Vitevitch, M. S. (2000). Phonetic priming, neighborhood activation, and PARSYN. Perception \& Psychophysics, 62, 615-625.

Marí-Beffa, P., Houghton, G., Estévez, A. F., \& Fuentes, L. J. (2000). Word-based grouping affects the prime-task effect on semantic priming. Journal of Experimental Psychology: Human Perception and Performance, 26, 469-479.

Marslen-Wilson, W., Nix, A., \& Gaskell, G. (1995). Phonological variation in lexical access: abstractness, inference and English place assimilation. Language and Cognitive Processes, 10, 285-308.

Marslen-Wilson, W., Tyler, L. K., Waksler, R., \& Older, L. (1994). Morphology and meaning in the English mental lexicon. Psychological Review, 101, 3-33.

Marslen-Wilson, W., \& Zwitserlood, P. (1989). Accessing spoken words: the importance of word onsets. Journal of Experimental Psychology: Human Perception and Performance, 15, 576-585.

McClelland, J. L., \& Elman, J. L. (1986). The TRACE model of speech perception. Cognitive Psychology, 18, 1-86.

McClelland, J. L., \& Rumelhart, D. E. (1981). An interactive activation model of context effects in letter perception: Part 1. An account of basic findings. Psychological Review, 88, 375-407.

McKoon, G., Allbritton, D., \& Ratcliff, R. (1996). Sentential context effects on lexical decisions with a cross-modal instead of an all-visual procedure. Journal of Experimental Psychology: Learning, Memory and Cognition, 22, 1494-1497.

McNamara, T. P. (1992). Theories of priming: I. Associative distance and lag. Journal of Experimental Psychology: Learning Memory and Cognition, 18, 1173-1190.

McQueen, J. M. (2005). Speech perception. In K. Lamberts \& R. Goldstone (Eds.), The handbook of cognition (pp. 255-275). London: Sage Publications.

McQueen, J. M., Cutler, A., Briscoe, T., \& Norris, D. (1995). Models of continuous speech recognition and the contents of the vocabulary. Language and Cognitive Processes, 10, 309-331. 
Meyer, D. E., \& Schvaneveldt, R. W. (1971). Facilitation in recognizing pairs of words: Evidence of a dependence between retrieval operations. Journal of Experimental Psychology, 90, 227-234.

Miller, G. A., Heise, G. A., \& Lichten, W. (1951). The intelligibility of speech as a function of the context of the test materials. Journal of Experimental Psychology, 41, 329-335.

Morton, J. (1969). The interaction of information in word recognition. Psychological Review, 76, 165-178.

Moss, H. E., \& Marslen-Wilson, W. D. (1993). Access to word meanings during spoken language comprehension: effects of sentential semantic context. Journal of Experimental Psychology: Learning, Memory and Cognition, $19,1254-1276$.

Neely, J. H. (1991). Semantic priming effects in visual word recognition: a selective review of current findings and theories. In D. Besner \& G. Humphreys (Eds.), Basic processes in reading: Visual word recognition (pp. 264-336). Hillsdale, NJ: Erlbaum.

Neely, J. H., \& Keefe, D. E. (1989). Semantic context effects in visual word processing: a hybrid prospective/retrospective processing theory. In G. H. Bower (Ed.), The psychology of learning and motivation: Advances in research and theory (Vol. 24, pp. 207-248). New York: Academic Press.

Norris, D. (1986). Word recognition: Context effects without priming. Cognition, 22, 93-136.

Norris, D. (1994). Shortlist: A connectionist model of continuous speech recognition. Cognition, 52, $189-234$.

Norris, D., McQueen, J. M., Cutler, A., \& Butterfield, S. (1997). The possible-word constraint in the segmentation of continuous speech. Cognitive Psychology, 34, 191-243.

Onifer, W., \& Swinney, D. A. (1981). Accessing lexical ambiguities during sentence comprehension: effects of frequency of meaning and contextual bias. Memory \&Cognition, 9, 225-236.

Ratcliff, R., \& McKoon, G. (1988). A retrieval theory of priming in memory. Psychological Review, 95, 385-408.

Salverda, A. P., Dahan, D., \& McQueen, J. M. (2003). The role of prosodic boundaries in the resolution of lexical embedding in speech comprehension. Cognition, 90, 51-89.

Seidenberg, M. S., Tanenhaus, M. K., Leiman, J. M., \& Bienkowski, M. (1982). Automatic access of the meanings of ambiguous words in context: Some limitations of knowledge-based processing. Cognitive Psychology, 14, 489-537.

Shatzman, K. B. (2006). Sensitivity to detailed acoustic information in word recognition. Ph.D. dissertation, Radboud University Nijmegen (MPI Series in Psycholinguistics, Vol. 37). Wageningen: Ponsen \& Looijen.

Shillcock, R. C. (1982). The on-line resolution of pronominal anaphora. Language and Speech, 25, 385-404.

Shillcock, R. C. (1990). Lexical hypotheses in continuous speech. In G. T. M. Altmann (Ed.), Cognitive models of speech processing: Psycholinguistic and computational perspectives (pp. 24-49). Cambridge, MA: MIT Press.

Simpson, G. B. (1981). Meaning dominance and semantic context in the processing of lexical ambiguity. Journal of Verbal Learning and Verbal Behavior, 20, 120-136.

Soto-Faraco, S., Sebastián-Gallés, N., \& Cutler, A. (2001). Segmental and suprasegmental mismatch in lexical access. Journal of Memory and Language, 45, 412-432.

Spinelli, E., McQueen, J. M., \& Cutler, A. (2003). Processing resyllabified words in French. Journal of Memory and Language, 48, 233-254.

Swinney, D. (1979). Lexical access during sentence comprehension: (re)consideration of context effects. Journal of Verbal Learning and Verbal Behavior, 18, 645-659.

Swinney, D., Onifer, W., Prather, P., \& Hirshkowitz, M. (1979). Semantic facilitation across sensory modalities in the processing of individual words and sentences. Memory \& Cognition, 7, 159-165.

Tabossi, P. (1988a). Effects of context on the immediate interpretation of unambiguous nouns. Journal of Experimental Psychology: Learning, Memory, and Cognition, 14, 153-162.

Tabossi, P. (1988b). Accessing lexical ambiguity in different types of sentential contexts. Journal of Memory and Language, 27, 324-340.

Tabossi, P. (1996). Cross-modal semantic priming. Language and Cognitive Processes, 11, 569-576.

Tabossi, P., Burani, C., \& Scott, D. (1995). Word identification in fluent speech. Journal of Memory and Language, $34,440-467$.

Tabossi, P., Collina, S., Mazzetti, M., \& Zoppello, M. (2000). Syllables in the processing of spoken Italian. Journal of Experimental Psychology: Human Perception and Performance, 26, 758-775.

Tabossi, P., Colombo, L., \& Job, R. (1987). Accessing lexical ambiguity: effects of context and dominance. Psychological Research - Psychologische Forschung, 49, 161-167.

Tabossi, P., \& Zardon, F. (1993). Processing ambiguous words in context. Journal of Memory and Language, 32, 359-372.

Tipper, S. P. (1985). The negative priming effect: inhibitory effects of ignored primes. Quarterly Journal of Experimental Psychology, 37 A, 571-590. 
Vroomen, J., \& de Gelder, B. (1995). Metrical segmentation and lexical inhibition in spoken word recognition. Journal of Experimental Psychology: Human Perception and Performance, 21, 98-108.

Vroomen, J., \& de Gelder, B. (1997). Activation of embedded words in spoken word recognition. Journal of Experimental Psychology: Human Perception and Performance, 23, 710-720.

Williams, J. N. (1988). Constraints upon semantic activation during sentence comprehension. Language and Cognitive Processes, 3, 165-206.

Zwitserlood, P. (1989). The locus of the effects of sentential-semantic context in spoken-word processing. Cognition, 32, 25-64.

Zwitserlood, P., \& Schriefers, H. (1995). Effects of sensory information and processing time in spoken-word recognition. Language and Cognitive Processes, 10, 121-136. 